\title{
Les argentières de Villemagne (Hérault) : exploitation de mines polymétalliques et enjeux territoriaux au Moyen Age central.
}

\author{
Nicolas MINVIELLE LAROUSSE*
}

Les mines polymétalliques (argent, cuivre, plomb) de Villemagne-l'Argentière, situées au nord du département de l'Hérault sur la bordure orientale de la Montagne Noire, ont fait l'objet d'une exploitation intense au cours du Moyen Âge central. L'activité minière et métallurgique inscrite en ces lieux a ainsi irrigué les économies et suscité des enjeux de pouvoirs pour les coseigneuries locales. Le rassemblement des sources textuelles et archéologiques permet de construire une synthèse des connaissances, tandis que leur commentaire croisé permet d'expliquer certaines pratiques des acteurs de la production, comme de révéler une partie des rapports qu'ils entretenaient.

Mots-clés : Mines, Moyen Âge, Languedoc, argent, cuivre, plomb, production métallurgique, production monétaire, coseigneurie.

\section{INTRODUCTION \\ Cadres de l'étude}

Dans le cadre d'une enquête universitaire centrée sur la production argentifère du Languedoc médiéval (Minvielle Larousse 2017), nous avons été amené à construire un programme de recherche spécifique sur les mines de Villemagne-l'Argentière, situées sur les contreforts orientaux de la Montagne Noire, au nord du département de l'Hérault (fig. 1). Le bourg abbatial, implanté au IX ${ }^{\mathrm{e}}$ siècle par des bénédictins sur les rives de la Mare (Journot 2013), était en effet au centre d'un vaste espace minier d'environ $130 \mathrm{~km}^{2}$, dont une large part de l'exploitation s'est déroulée au Moyen Âge central. Cette contribution présente donc les premiers résultats obtenus tout en rassemblant les connaissances, nombreuses mais dispersées, dont nous disposons sur un espace qui fut l'une des principales sources de minerais polymétalliques (argent, plomb, cuivre) du Languedoc médiéval.

\section{Historiographie}

En dehors des classiques Histoire Naturelle et Histoire Générale de Languedoc (Gensanne 1779 ; Vic, Vaissète 1874), Joseph Poux a été en 1899 le premier à éditer et à commenter plusieurs textes miniers issus du fonds Thésan (Poux 1899). Son objet était l'exploitation médiévale du charbon de terre dans les formations carbonifères de Boussagues et de Graissessac. Ce dossier sur le charbon de terre a été repris en 1999 par Catherine

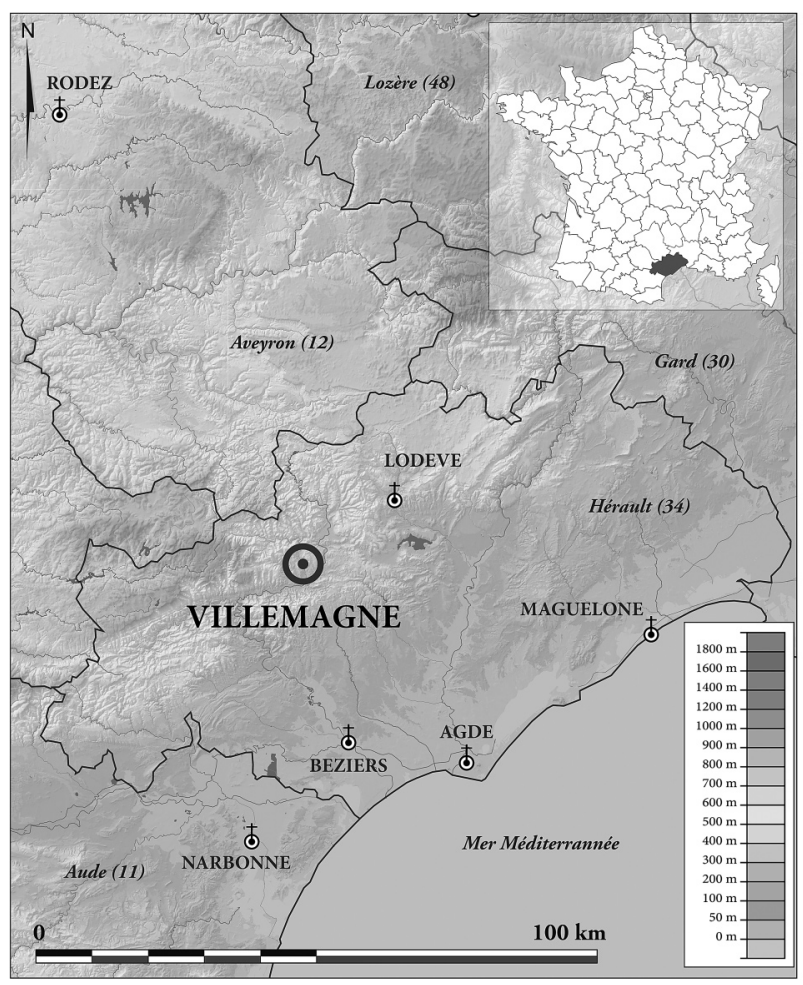

Fig. 1 : Localisation de Villemagne.

Verna (Verna 1999). Le travail de Joseph Poux précédait de peu l'entreprise des archivistes Pasquier et Olive. Entre 1900 et 1913, ils ont publié inventaires et éditions

\footnotetext{
* Aix Marseille Univ., CNRS, LA3M, Aix-en-Provence, France.
} 
de ce fonds qui allait servir à plus d'un chercheur (Pasquier 1900; 1901 ; Pasquier, Olive 1913). Après les travaux de Philippe-Jean Hesse en 1968 qui en avait déjà tiré plusieurs exemples (Hesse 1968), il fallut attendre 1977 pourtant, pour que les médiévistes languedociens s'emparent de la question minière. Claudie Amado a d'abord exhumé et commenté une convenientia de 1164 ayant pour objet la création d'une coseigneurie minière, dans le cadre de ses recherches biterroises (Amado 1977 ; 2001 ; 2007). Mais c'est en marge de la thèse de Florence Journot, portant sur les castra de l'Hérault, que la problématique minière a été construite (Journot 1990). Elle consacre peu après un article aux mines de Villemagne (Journot 1992) et développe davantage le thème dans une monographie récente du bourg abbatial (Journot 2013).

Malgré cette longue tradition, la pratique du terrain a d'abord été géologique. Dans le sillage des recherches minières de la première moitié $\mathrm{du} \mathrm{XX}^{\mathrm{e}}$ siècle, la thèse gîtologique d'Henri Gonord, soutenue en 1966 et portant sur les gîtes minéraux de la terminaison orientale de la Montagne Noire, a fait la synthèse des nombreux travaux spécifiquement géologiques et des divers rapports et études produits par les géologues miniers (Gonord 1966). Nous renvoyons à sa bibliographie pour le détail. Il a porté une attention particulière aux travaux anciens, a reproduit plusieurs plans de réseaux récents, tout en produisant de précieuses notices géologiques et gîtologiques par secteur et gîtes minéraux. En complément de cette synthèse, nous disposons de nombreuses fiches de prospection établies dans les années 1970 par l'abbé d'Andabre, Aimé-Henri Boulanger. Conservées aux archives du BRGM, ces fiches localisent et décrivent la plupart des travaux miniers du secteur. Il s'est principalement attaché aux travaux récents, mais a enregistré à chaque fois qu'il en voyait les travaux anciens.

Puis, le secteur a fait l'objet de plusieurs prospections et fouilles d'archéologie minière, en particulier antique. Robert Gourdiole mena quelques opérations dans la vallée de la Mare avant de concentrer ses fructueuses recherches dans les monts d'Orb (Guiraud, Gourdiole 1978 ; Gourdiole, Guiraud 1992). Les vallées de la Mare et de Lamalou ont ensuite fait partie de l'inventaire des mines antiques effectué par Raphaël de Filippo, Yvonne Gracia, Xavier Peixoto et Christine Sauvage en 1981 et 1982 (Filippo et al. 1982 ; Cambon et al. 1986). Plus récemment, Julien Mantenant a proposé dans sa thèse, soutenue en 2014, une synthèse critique des apports de l'ensemble des travaux précédents, tout en les replaçant dans le contexte minier de la Gaule méridionale (Mantenant 2014).
Cependant, les phases médiévales n'étaient que peu abordées par les antiquistes. Afin de remédier à cet état de la recherche pour le moins inégal au regard de son potentiel, Béatrice Béchiri avait commencé un mémoire de maîtrise. Elle a effectué des prospections dans la vallée de Lamalou et à Boussagues en 1999 et 2001 (Béchiri 1999 ; 2001), mais son travail universitaire est resté malheureusement inachevé (1).

\section{Objectifs et problématiques}

Sur ces fondations, nos objectifs étaient triples. D'abord, rassembler le corpus textuel afin de tracer les lieux et les rythmes de la production médiévale. Beaucoup étaient connus, mais restaient dispersés (2). Ensuite, construire un corpus archéologique comprenant l'ensemble des vestiges médiévaux, ou potentiellement médiévaux. Cette tâche a été engagée à l'aide de la bibliographie géologique et archéologique, et complétée par une campagne de prospection en 2016 (3). Enfin, et surtout, préciser l'organisation de la production médiévale en confrontant les données issues des textes et des terrains. Ces objectifs sont autant d'étapes dans une recherche qui aura vocation à se poursuivre à Villemagne, comme dans d'autres espaces miniers, pour nourrir des problématiques relatives aux systèmes de production médiévaux, entre occupation et exploitation des sols, techniques et organisation du travail.

\section{L'ESPACE MINIER DE VILLEMAGNE}

Cette première partie présente les cadres de la production, tout en mettant spécifiquement en lumière sa phase médiévale, objet des prospections.

\section{Localisation des exploitations}

Avant d'entrer dans le détail, précisons le contour de l'exploitation médiévale (fig. 2). Il est bien connu depuis que Claudie Amado a identifié le « quadrilatère argentifère » de Villemagne au travers d'un accord conclu en 1164 entre Raymond Trencavel, vicomte de Béziers et Ermengarde, vicomtesse de Narbonne (Amado 1977). La concession correspond à une délimitation faite à l'aide de points de repère, complétée par le territoire des castra cités. En peu de mots, elle correspond d'abord à une surface de $80 \mathrm{~km}^{2}$ circonscrite de Faugères au château de Mourcairol, au château du Poujol, au mont Mayres, à Maurian, au château de Boussagues, à Bédarieux, à Soumartre pour boucler à Faugères. À cet espace, il faut ajouter les ressorts des châteaux de Mourcairols, du Poujol et de Boussagues (4). Deux transactions entre

\footnotetext{
${ }^{1}$ Université de Provence, sous la direction de Marie-Christine Bailly-Maître et Michel Fixot.

${ }^{2}$ Pour consulter le Regeste des textes de l'espace minier de Villemagne, nous renvoyons à sa monographie contenue dans le volume 2 de notre thèse, ou au Regeste des mines argentifères du Languedoc oriental contenu dans son volume 3 (Minvielle Larousse 2017).

${ }^{3}$ Le rapport d'opération est consultable au Service Régional de l'Archéologie Occitanie, à Montpellier (Minvielle Larousse 2016).

${ }^{4}$ BNF, DOAT 167, fo 274-276. "Haec est carta de concordia inter Raymundum Trencavelli Biterris vicecomitem et Hermengaudam Narbonae vicecomitissam facta de argentariis et mineriis, quae modo sunt aut in antea fuerunt inventa, a Saugueria usque ad castrum de Mercoirol et a castro Mercoirol usque ad castrum de Pojols et a castro de Pojols usque ad Montmaires et a collo de Montmaires usque ad Maurianum et a Mauriano usque ad castrum de Bociagas et a castro de Bociagas usque ad Bedeirias et de Bedeiriis usque ad villam de Samarde et a villa de Samarde usque ad Saugueria. Et omnes argentarias vel minarias, quae modo sunt et in antea inventa fuerunt infra praedictos terminos vel in terminiis praedictorum castrorum [...]».
} 


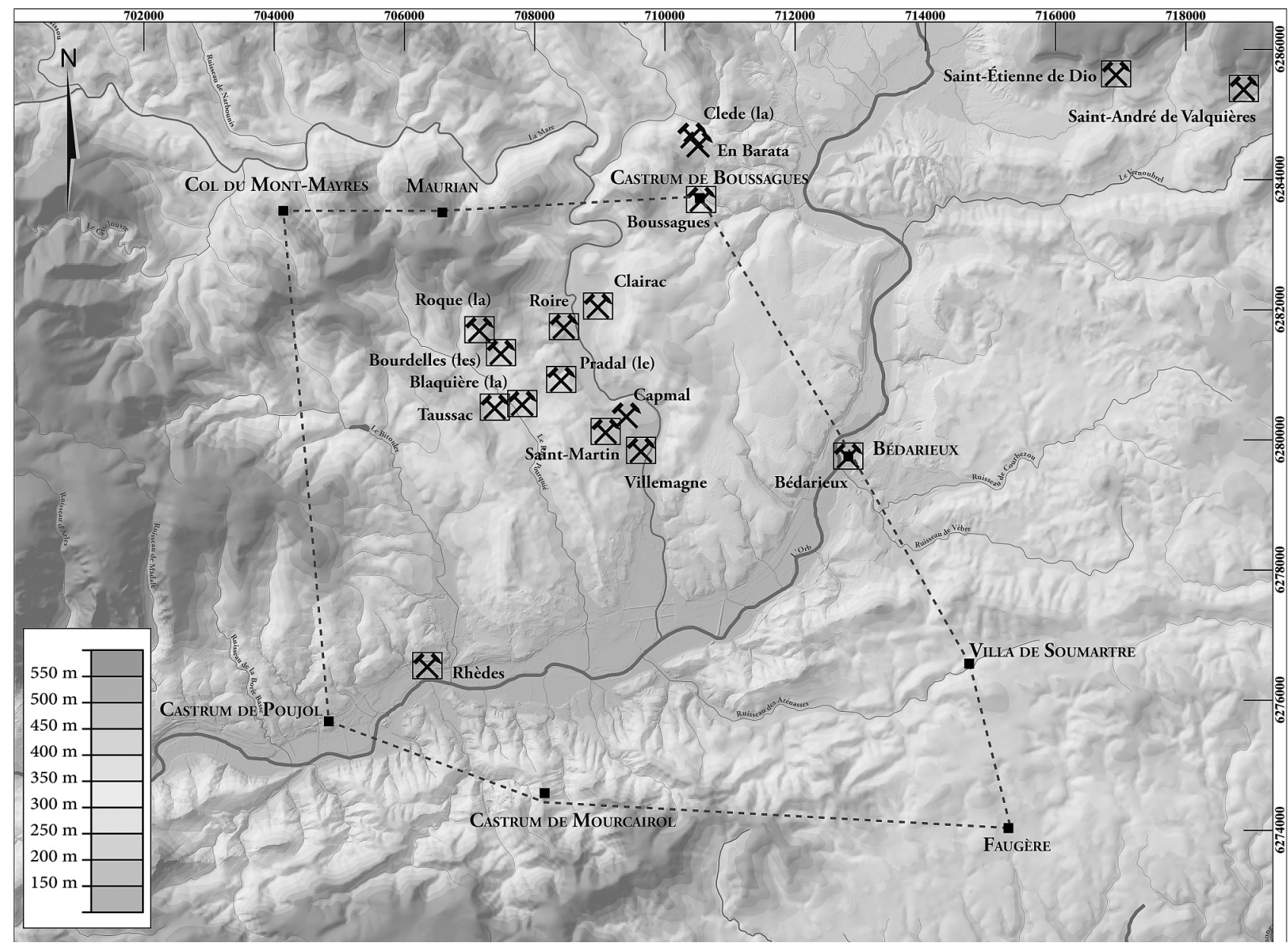

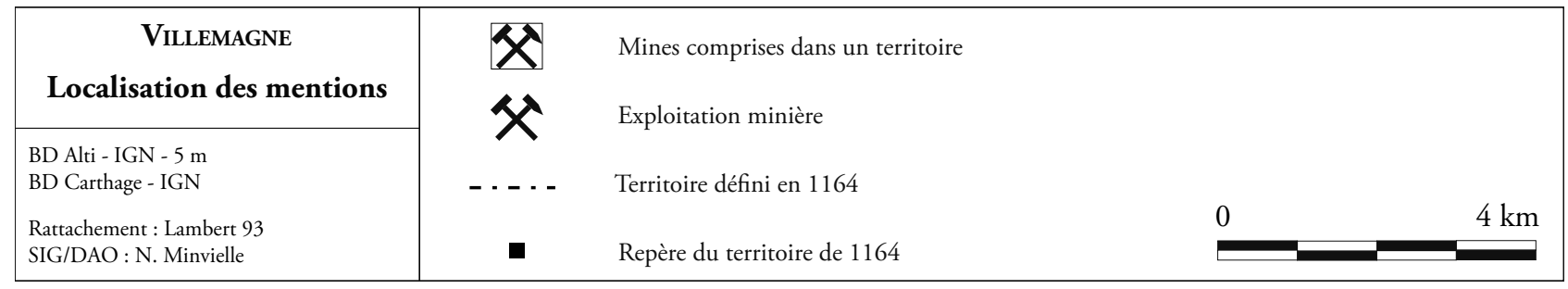

Fig. 2 : Localisation des mentions médiévales des mines argentifères de Villemagne.

Guillaume Aton et Déodat de Boussagues élargissent en théorie le périmètre argentifère. Le premier recevait en gage en 1199, puis achetait en 1207 les biens du second, dont ceux situés sous terre (5). Les échanges concernent un espace élargi au nord puisque l'on est entre le Dourdou et l'Orb, et élargi à l'ouest avec comme limite le ruisseau d'Héric. Cependant, au contraire de l'accord de 1164, ces actes ne concernent pas seulement les mines, mais l'ensemble des biens de Guillaume Aton. Sa valeur pour localiser les mines est donc moindre.
Il faut croire que la concession de 1164 a été tracée en toute connaissance du potentiel minier du secteur, car l'ensemble des territoires contenant des mines citées par la suite, ou presque, se situe dans ses limites. C'est d'abord le cas des paroisses de Saint-Pierre de Rhèdes, de Saint-Alexandre de Bédarieux, de Saint-Martin-leVieux et de Saint-Saturnin de Clairac. Les seules qui sont au-delà sont celles de Saint-Étienne de Dio et de SaintAndré de Valquières (6). Les territoires castraux concernés sont ceux de Boussagues, de Clairac, Taussac et Villemagne (7).

${ }^{5} 1199$ : AD 09, 46J 644 (Pasquier, Olive 1913, 57-58). 1207 : AD 09, 46J 644 (Pasquier, Olive 1913, 65-68).

${ }^{6}$ Saint-Pierre de Rhèdes est citée en 1182/1183 (Rouquette 1918, 403-405, n CCLXXXV) ; Saint-Alexandre de Bédarieux est citée en 1199 (AD 09, 46J 644, Pasquier, Olive 1913, 57-58) ; les 4 autres sont citées en 1263 (AD 09, 46J 641, Pasquier, Olive 1913, 252-256).

${ }^{7}$ Boussagues et Rhèdes sont mentionnés la première fois en juillet 1189 (BNF, Doat $\mathrm{n}^{\circ} 40$, $\mathrm{f}^{\circ} 111$, Mahul 1857, t. V, p. 283-284) ; Clairac et Taussac en septembre 1199 (AD 09, 46J 644, Pasquier, Olive 1913, 57-58) ; Villemagne en 1173 (BNF, Doat, vol. 40, fo 98-101v, Débax 2008, t. 2, p. 332-334). 
Plus précises sont les indications d'exploitations comprises dans l'alleu de Saint-Martin ainsi que les manses de Roca, de la Blaquière, de Roire, des Bourdelles, du Pradal et de Caurtas (8). C'est moins assuré pour ce dernier, car les mines ne sont pas citées indépendamment, mais incluses dans le formulaire énumérant l'ensemble des droits attachés au manse. Enfin, quelques exploitations sont citées directement. C'est probablement le cas en 1233 du minario de Tauciaco et du minario de Capmal, certainement celui des galeries de Boussagues en 1237 et 1289 : Agrofolio, La poleia, La cleda et En Barata (9). Compte tenu de leur proximité, il est possible que le minier de Capmal, cité en 1233, renvoie aux mines de l'alleu de SaintMartin, citées en 1210 (10).

De tous ces lieux, seuls quelques-uns ne sont pas évidents à localiser : les manses de Roca, de Roire de Caurtas ; et les galeries de Boussagues. Roca et Roire sont cités avec d'autres lieux situés aux alentours du Pradal ; nous supposons donc qu'ils leur sont proches. Deux toponymes liés à Roca, Roquessoule et la Roque rouge, figurent sur la carte IGN au nord des Bourdelles, ils pourraient hypothétiquement s'y référer. Les plans du $\mathrm{XIX}^{\mathrm{e}}$ siècle des ingénieurs des mines ont permis de placer avec plus d'assurance le manse de Roire : il serait proche de l'un des ravins situés au nord du Pradal, nommé Rouire (11). En revanche, le manse de Caurtas reste dans l'ombre, il est juste rattaché à la paroisse de Sainte-Marie de Taussac. À Boussagues, les toponymes ont disparu. Le bail de 1237 place les galeries proches les unes des autres (12). Elles se trouvent non loin de l'honor de Jordani de Mala veilla et en deçà d'un chemin qui va apud Aream Roemon. L'Aire Raymond correspond à l'extrémité orientale du mont Coudour. Deux chemins y mènent, l'un partant du nord, l'autre du sud, si bien que nous ne pouvons en l'état préciser davantage leur position.

\section{Les terrains exploités :}

\section{le bassin sédimentaire de Bédarieux}

Ainsi délimité, l'espace minier médiéval s'étend sur la bordure orientale de la Montagne Noire, un massif issu de l'orogénèse varisque, vestige d'une chaîne de montagnes formée au cours du paléozoïque qui s'étendait alors de l'Oural à l'Amérique du Nord (Gèze 1995 ; Charles et al. 2009). Il se compose de roches métamorphisées, c'est-à-dire transformées par des élévations de températures et de pression, en l'occurrence des granites, des schistes, des gneiss et parfois des dolomies massives du Cambrien (fig. 3).
Les travaux miniers se trouvent plus exactement au contact d'un bassin sédimentaire, dit de Bédarieux, formé dans un second temps contre la bordure orientale du massif varisque, à la suite de la transgression marine du Mézozoïque. Les roches du bassin se composent d'abord de grès massifs (Trias inférieur), se suivent avec des argiles gréso-dolomitiques et s'achèvent par des dolomies et des calcaires (Lias inférieur). Les formations sédimentaires ont largement recouvert le socle métamorphique, mais ce dernier affleure toujours à quelques endroits, notamment entre Taussac et le Pradal. Le bassin de Bédarieux se limite à l'ouest par la zone axiale de la Montagne Noire, au sud par son versant méridional et au nord-est par un bassin sédimentaire antérieur, formé au Permien, dit de Lodève (Lamotte et al. 2011).

Plusieurs accidents tectoniques marquent la limite ouest du bassin, dont la faille de Lamalou/Boussagues au nord-ouest, le long de laquelle se concentrent les mentions citées dans les textes. Orientée nord-est/sudouest, puis nord/sud au niveau de la ville de Lamalou, elle s'étire sur $10 \mathrm{~km}$ de Boussagues à Rhède, en passant au nord de Taussac. Elle marque une limite franche entre les calcaires dolomitiques du bassin de Bédarieux au sud-est et l'ensemble schisto-gréseux de la Montagne Noire au nord-ouest, parfois par l'intermédiaire d'un dyke (crête) de dolomie et de quartz.

En somme, l'espace minier s'est formé sur deux principaux terrains géologiques : un substrat de roches métamorphiques (Paléozoïques) et une couverture de roches sédimentaires (Mésozoïques). Les dynamiques tectoniques ont en outre favorisé la concentration de minéralisation, en particulier au contact de ces deux terrains.

\section{L'objet des recherches : des minerais polymétalliques de cuivres et de galènes argentifères}

D'après les données réunies par Henri Gonord, les minéralisations du bassin de Bédarieux se sont formées au cours de plusieurs étapes métallogéniques (Gonord 1966, 129-131). Primo, certains filons B.P.G. (blende/sphalérite, pyrite, galène) associés à de la barytine sont tardi-varisques, comme les dykes quartzeux. Ces gîtes sont pauvrement minéralisés en cuivre gris. Secundo, les gîtes triasiques du bassin de Bédarieux sont contemporains à la transgression marine. La forme des gîtes est variée : filonnets sub-horizontaux et mouches de sulfures dans les grès ; filons de baryte définis ; amas de baryte avec imprégnations locales des grès dans les zones de failles ; amas de quartz/baryte dans les marnes ; filonnets de cuivre gris ; minéralisations sub-stratiformes riches en cuivres gris (Gonord 1966, 112). Tertio, d'autres

\footnotetext{
${ }^{8}$ La Roque est mentionnée pour la première fois le 30 juin 1209 (AD 09, 46J 644, Pasquier, Olive 1913, 68-71) ; les 4 suivants le sont en 1233 (AD 09, 46J 644, Pasquier, Olive 1913, 76-94) ; le manse de Caurtas est signalé en 1268 (AD 09, 46J 644, Pasquier, Olive 1913, 110-112) ; l'alleu de SaintMartin est cité en 1210 (BNF, Doat, vol. 55, fo . 257, Boussard, Monicat 1946, 212-215, $\mathrm{n}^{\circ} 1120$ ).

${ }^{9} 1233$ : AD 09, 46J 644 (Pasquier, Olive 1913, 76-94). 1237 : AD 09, 46J 644 (Pasquier, Olive 1913, 94-96). 1289 : AD 09, 46J 644 (Pasquier, Olive 1913, 123-124).

${ }^{10} 1233$ : AD 09, 46J 644, (Pasquier, Olive 1913, 76-94). 1210 : BNF, Doat, vol. 55, f $\mathrm{f}^{\circ} .257$ (Boussard, Monicat 1946, 212-215, n 1120).

${ }^{11} \mathrm{AD} 34,8 \mathrm{~S} 171$.

${ }^{12} 1237$ : AD 09, 46J 644 (Pasquier, Olive 1913, 94-96).
} 


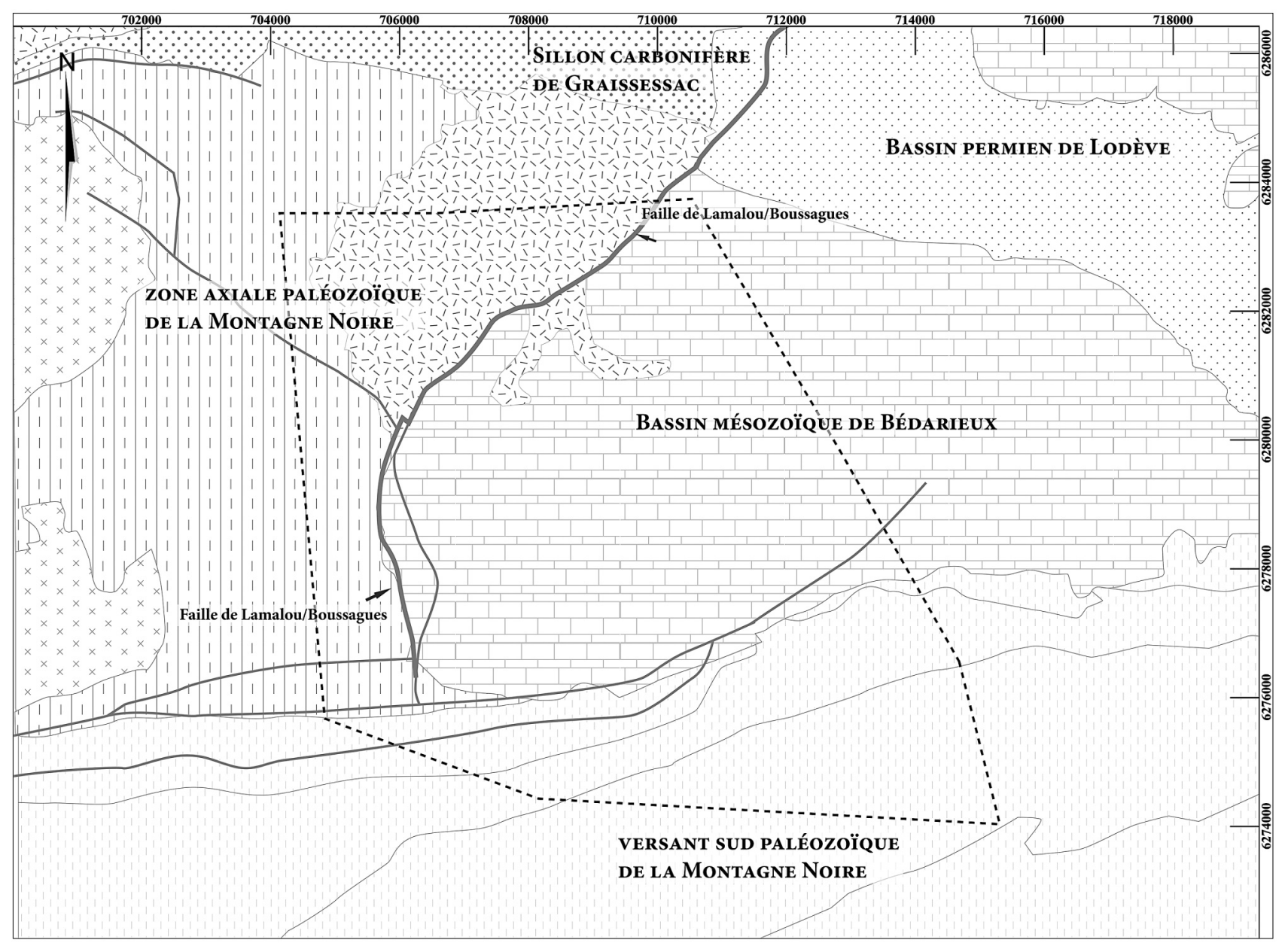

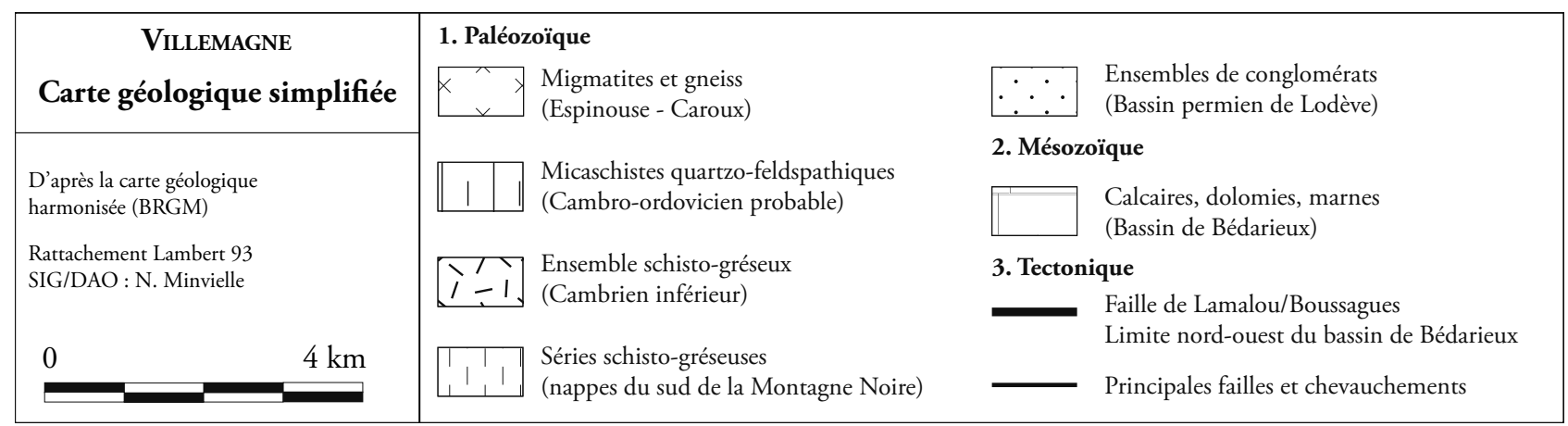

Fig. 3 : Carte géologique simplifiée.

gîtes se sont formés dans une phase post-triasique, d'origine hydrothermale et sont principalement composés de sulfures et arséniures cuivreux. On verra plus loin qu'en l'état des connaissances, les deux premiers types de minéralisation ont fait l'objet des exploitations anciennes.

\section{Chronologie des travaux}

La synthèse chronologique repose sur un état de la recherche destiné à évoluer, en particulier avec le développement d'opérations archéologiques. Pour l'heure, les textes forment son principal support.

\section{Les exploitations médiévales}

Avant de proposer un phasage et pour en permettre la critique, il convient de présenter brièvement l'état de conservation des archives. Deux phases se distinguent dans la production documentaire. La première est celle de la haute aristocratie : elle s'étend de la convenientia de 1164 aux engagements contractés par les vicomtes de Béziers à la fin du XII ${ }^{\mathrm{e}}$ siècle en passant par les conflits dimiers des évêques de Béziers. Ces textes proviennent essentiellement des grands cartulaires, laïcs et ecclésiastiques. Il nous manque cependant celui de Villemagne (13) et la documentation produite par la petite aristocratie. La

\footnotetext{
${ }^{13}$ Les archives de l'abbaye de Villemagne sont conservées aux archives départementales de l'Hérault (AD 34), dans la sous-série 8H. Peu d'actes concernent les périodes antérieures au XVI siècle en raison des destructions des guerres de religions.
} 
seconde phase débute avec l'ascension des seigneurs de Boussagues. Une partie de leurs archives est contenue dans le fond Thézan, un chartrier seigneurial aussi précieux que rare (Blaquière 1998) (14). Il n'en reste pas moins partiel et contribue peut-être à surestimer le rôle des Boussagues dans la production. Malgré tout, il nous offre par sa continuité une bonne vision de l'abandon des exploitations polymétalliques, entre la moitié du $\mathrm{XIII}^{\mathrm{e}}$ siècle et le début du $\mathrm{XIV}^{\mathrm{e}}$ siècle.

Phase 1 : avant 1164. Loin d'être un point de départ, l'acte de 1164 montre implicitement que plusieurs gisements étaient déjà en exploitation (15). Établi en fonction des travaux présents, voire passés, il permettait aussi de prévoir l'avenir en laissant la possibilité d'élargir encore les travaux tout en restant dans ses cadres. La course aux revenus miniers, a fortiori si elle génère des conflits, s'entend mieux si les exploitations sont existantes et suffisamment avancées pour être bénéficiaires. L'année 1164 marque donc un premier apogée de la production avec une extension spatiale certaine et une production qui paraît dynamique.

Phase 2 : 1164-1233. La croissance est d'autant plus crédible qu'elle ne semble pas s'arrêter. Les investissements opérés par les Boussagues entre 1199 et 1233 suggèrent que les revenus miniers étaient toujours attrayants, assez en tout cas pour alimenter un nouveau conflit avec l'abbaye (16).

Phase 3 : 1233-1268. Un accord de 1233 conclu entre les coseigneurs locaux (Abbaye de Villemagne, seigneur de Boussagues, de Faugères) marque en revanche un palier. En comparant les exploitations citées en 1233 et celles d'un testament de 1263, on observe un déplacement des droits miniers de Déodat de Boussagues (17). Les manses du Pradal, de Capmal, de Roire, des Bourdelles, de la Blaquière et de la Roque ne sont plus mentionnés, alors que des mines sont signalées, pour la première fois, dans les paroisses de Dio et de Valquières. Soit ces différences s'expliquent par l'abandon de redevances entre 1233 et 1263, soit l'élargissement oriental de l'espace minier est le fruit de nouvelles prospections destinées à compenser le ralentissement, voire la fin des travaux dans plusieurs des gisements du pourtour de Villemagne. Cette dernière hypothèse est corroborée par l'hommage rendu aux Boussagues pour le manse de Caurtas en 1268 ; la présence des mines dans la liste des droits indiquerait une nouvelle phase de prospection dans la paroisse de Taussac, soit la prise en compte prudente d'une découverte future (18). Ainsi, il est probable qu'entre 1233 et 1268 , la production se soit déplacée et amoindrie. L'une des conséquences pourrait être l'effacement de l'abbaye dans la production. Elle ne semble pas avoir suivi le déplacement de l'activité.

Phase 4 : après 1268 . La nouvelle concession de la galerie d'En barata, faite à Boussagues en 1289, puis les concessions de 1303 et 1333 de mines à La Blaquière puis au Pradal sont les dernières entreprises polymétalliques du secteur (19). Contrairement au démarrage, l'arrêt des travaux est bien borné. Il coïncide avec le développement de l'extraction de charbon de terre au nord de Boussagues, ce qui nous permet d'être plus assurés sur ce terminus, car les sources ne sont pas en cause (20). La bonne conservation du chartrier des Boussagues au XIV ${ }^{\mathrm{e}}$ siècle offre de nombreux actes notariés relatifs au charbon ; ils auraient aussi concerné la production argentifère si elle avait perduré (21).

Ainsi, les exploitations polymétalliques de Villemagne connaissent une longue phase de croissance depuis la moitié du XII ${ }^{\mathrm{e}}$ siècle au plus tard, jusqu'en 1233 (fig. 4). Entre cette date et 1268, elles régressent pour s'arrêter dans la première moitié du XIV siècle. La principale inconnue, au-delà des biais inhérents à la production et à la conservation des textes, est le démarrage des travaux. La convenientia de 1164 induit en effet une parfaite connaissance du potentiel métallifère. Sans doute que les prospections étaient déjà achevées, sinon bien avancées. Soit on considère que les travaux débutent massivement dans la première moitié du XII ${ }^{\mathrm{e}}$ siècle, soit on considère que la croissance est plus diffuse et a débuté plus tôt.

\footnotetext{
${ }^{14} \mathrm{Il}$ est actuellement conservé aux archives départementales de l'Ariège (AD 09) sous la côte 46J. Son inventaire a été réalisé lorsqu'il était aux archives nationales (AN), sous la cote $436 \mathrm{AP}$

${ }^{15}$ BNF, DOAT 167, fo 274-276 (Amado 1977).

${ }^{16} 1199$ : AD 09, 46J 644 (Pasquier, Olive 1913, 57-58). 1233 : AD 09, 46J 644 (Pasquier, Olive 1913, 76-94).

${ }^{17} 1263$ : AD 09, 46J 641 (Pasquier, Olive 1913, 105-109).

${ }^{18} 1268$ : AD 09, 46J 644 (Pasquier, Olive 1913, 110-112).

${ }^{19} 1289$ : AD 09, 46J 644 (Pasquier, Olive 1913, 123-124). 1303 : AD 09, 46J 605, liasse 70, $\mathrm{n}^{\circ} 28$. Inventaire des titres de Boussagues établi en 1665. 1333 : AD 09, 46J 605, liasse 70, $\mathrm{n}^{\circ}$ 20. Inventaire des titres de Boussagues, sans date (moderne).

${ }^{20}$ L'effacement de la production argentifère s'observe aussi dans les testaments de Déodat (fils) et Pierre de Boussagues, établis respectivement en 1334 et 1348. Aucune des mines citées dans le testament de Déodat (père) de 1263 n’y figurent : AD 09, 46J 641 ; Fonds Thézan, liasse 106, n 7 (copie $\mathrm{XIV}^{\mathrm{e}}$ siècle ?).

${ }^{21}$ La succession des productions argentifères puis carbonifère est toutefois à nuancer. En effet, l'exploitation carbonifère est active dès le début du XIII ${ }^{\mathrm{e}}$ siècle. Un inventaire ancien signale une concession faite en 1230 par Déodat de Boussagues à Guillaume Casserabes de Frangouille. AD 09, 46J, liasse $70, \mathrm{n}^{\circ}$ 20. Inventaire des titres de Boussagues, sans date (moderne). Puis, une transaction conclue en 1238 sur la charbonnière de las Balmas à Camplong. Elle correspond probablement au lieu de las miniere, acquis en 1237 par Déodat de Boussagues. Celle-ci est mentionnée par la suite en 1280, en 1342, 1344, 1376 et en 1388. AD 09, 46J, liasse 70, $\mathrm{n}^{\circ} 28$. Inventaire des titres de Boussagues rédigé en 1678 . Il arrive que les inventaires anciens soient fautifs sur l'objet de l'exploitation, ainsi la concession de 1237 est parfois notée comme houillère. Néanmoins, les analyses de 1230 et 1238 paraissent crédibles. De plus, les productions argentifère et carbonifère auraient été, un temps, concomitantes, ainsi que le suggère cette mention : Item in usaticis argenti et carboneriis, triginta solidos turonenses. Elle provient d'une copie, produite en 1672, du dénombrement que Guillaume de Thézan, seigneur du Poujol, a produit à l'occasion de son hommage au roi. Plusieurs seigneurs du Thézan se prénomment Guillaume, cela nous placerait à la fin du $\mathrm{XIV}^{\mathrm{c}}$ ou au XV $\mathrm{XV}^{\mathrm{e}}$ siècle. Compte tenu de la date tardive, peut-être qu'une reprise ponctuelle de la production argentifère n'est pas à exclure. AD 09, 46J 605, liasse 70, n 20.
} 


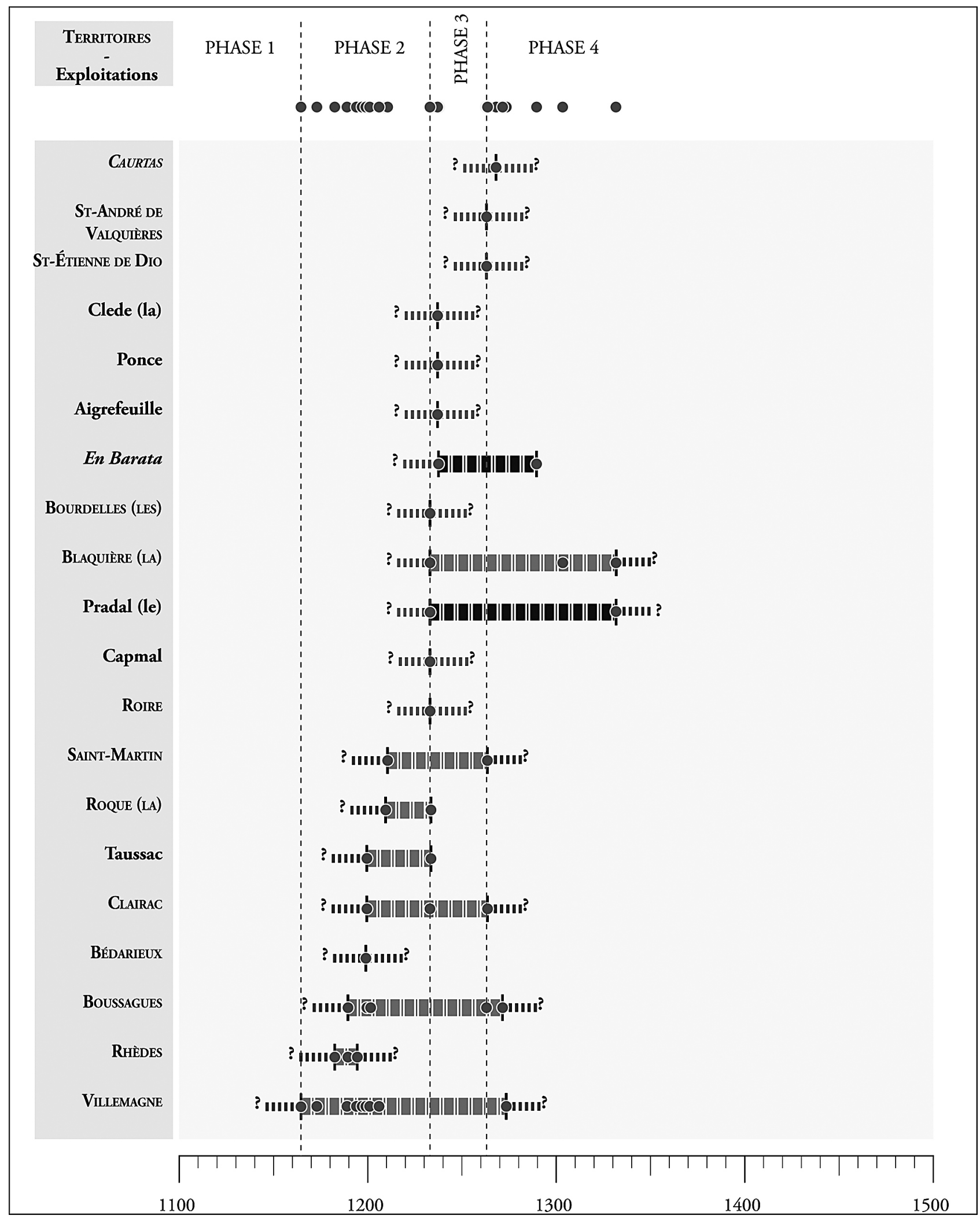

\begin{tabular}{|c|c|c|c|}
\hline $\begin{array}{c}\text { VILLEMAGNE } \\
\text { Chronographie } \\
\text { (1164-1333) }\end{array}$ & ?.....। & $\begin{array}{l}\text { Production (continue ou discontinue) } \\
\text { Terminus post-quem de l'activité }\end{array}$ & $\begin{array}{l}\text { Texte en rapport avec les mines } \\
\text { Première et dernière mention textuelle }\end{array}$ \\
\hline DAO : N. Minvielle & .....? & Terminus ante-quem de l'abandon & Phasage de la production \\
\hline
\end{tabular}

Fig. 4 : Chronographie de la production argentifère de Villemagne. 


\section{Les indices antérieurs au Moyen Âge}

Pour le moment, nous ne connaissons pas d'indices d'exploitation pré, ni proto-historique. Rien ne s'y oppose toutefois, ne serait-ce qu'en raison de la proximité des mines de Cabrières, exploitées depuis le Chalcolithique, ou d'autres travaux miniers et métallurgiques connus pour ces périodes en plusieurs lieux de la Montagne Noire, par exemple à Lastours (Ambert et al. 1996 ; Munteanu et al. 2017).

En revanche, la tradition antique est vive à Villemagne, en particulier sur la mine argentifère du Pradal, depuis qu'Alfred Daubrée a rapporté la découverte d'une monnaie antique à $80 \mathrm{~m}$ de profondeur (22). Monique Clavel est plus affirmative en indiquant la présence en contrebas du Pradal d'un épandage de céramiques (campaniennes, sigillées, amphores), associées à 4 monnaies datées de la fin du $\mathrm{I}^{\text {er }}$ siècle av. n. è. au $\mathrm{I}^{\mathrm{er}}$ siècle de n. è. (Clavel-Lévêque 1970, 331 ; Léchelon 2011, 266). Comme c'est manifestement tout ce qui alimente cette tradition au Pradal, nous devons rester prudents. Les prospections de Robert Gourdiole ont identifié un autre épandage (ou serait-ce même ?) de mobilier antique légèrement plus au nord du Pradal, à Grogues. Des scories y sont associées, mais comme de la céramique médiévale y est aussi mêlée, impossible de le confirmer sans sondage (Guiraud, Gourdiole 1978 ; Béchiri 1999, 23-25). Des travaux situés plus à l'ouest vers le col de Roujas, seraient aussi associés à du mobilier céramique antique (Filippo et al. 1982, vol. 2, p. 36 ; Béchiri 1999, 23-25). Une dernière indication a été relevée : une épitaphe découverte à Villemagne mentionne un personnage de la tribu Pollia, autrement dit un colon italien de la première déduction de Narbonne, qui serait venu fonder un domaine rural, au $\mathrm{I}^{\mathrm{er}}$ siècle av. n. è. (Bellan, Christol 1986) (23). Comme le supposent Marie-Luisa Bonsangue et Julien Mantenant, la présence précoce de Narbonnais dans cet espace pourrait ainsi suggérer une exploitation de ses ressources minières, d'autant qu'au même moment les mines de Rocozels, situées à quelques kilomètres au nord de Villemagne, étaient largement mises en valeur par les colons de l'agglomération de Lascours (Bonsangue 2011 : 369-370 ; Mantenant 2014 : 338). Il reste toutefois à confirmer ces indices par la datation des travaux miniers, car occupation ne signifie pas nécessairement exploitation.

\section{Les reprises postérieures au Moyen Âge}

Les travaux anciens n'avaient en tout cas pas totalement épuisé ces gisements. Plusieurs reprises, ou, du moins, tentatives de reprises se sont succédées au cours des $\mathrm{XIX}^{\mathrm{e}}$ et $\mathrm{XX}^{\mathrm{e}}$ siècles. Nous n'avons pas pour objet de détailler ici ces phases contemporaines ; seulement de fixer ses principales lignes pour permettre le lien avec l'état actuel des vestiges.

Le dépouillement des archives de l'intendance du Languedoc (AD34, Série C) a été négatif pour ce secteur. Les premières reprises sérieuses se manifesteraient donc à partir de 1833 avec la demande en concession d'une mine de plomb à Rougas (24). En 1841, les gisements plombifères du Pradal font l'objet de plusieurs demandes en concession et de quelques travaux de recherche, essentiellement centrés sur le coteau au nord du village (25). En 1855, la concession des mines de l'AireRaymond (La Tour-sur-Orb, proche de Boussagues) est formalisée à des fins de recherches de gisements de plomb, cuivre et or (26). À partir de 1858, les activités s'étendent avec une compagnie anglaise qui sollicite et obtient en 1865 la concession des mines de Villecelle et Villemagne. Or, les exploitants se heurtent rapidement à l'opposition des établissements thermaux de la vallée de Lamalou (27). En 1871, une autre entreprise, la Société anonyme des Usines à Zinc du Midi, obtient un permis de recherche étendu aux communes d'Hérépian, Villemagne, Taussac, Le Pradal, Le Poujol, Villecelle, Saint-Gervais, Boussagues, et Saint-Martin d'Orb (28).

Par la suite, la Société Vieille Montagne (SVM) a repris la concession de Villecelle et conduit plusieurs travaux d'exploitation ou de recherche au cours du $\mathrm{XX}^{\mathrm{e}}$ siècle. Des reprises aux mines de Lacan sont ainsi signalées entre 1890 et 1899 pour l'exploitation d'oxydes de zinc et de sphalérites, un puits est creusé pour atteindre la mine Saint-James, au nord du Pradal, en 1907, des recherches (puits et galeries) sont signalées à Taussac en 1910 (Gonord 1966, 104). Enfin, des travaux plus importants s'effectuent sur le Mont-Coudour de 1930 à 1933, puis de 1958 à 1959. En 1958 enfin, une campagne de sondages s'est concentrée sur le versant dolomitique de l'Abbaisse (Gonord 1966, 121). La concession, détenue depuis 1884 par la Société Vieille Montagne (devenue Union Minière, puis Umicore) a été renoncée en 2001 (Légifrance).

\section{LES VESTIGES DES EXPLOITATIONS ANCIENNES}

Les prospections se sont donc confrontées à des travaux anciens vraisemblablement diachroniques, en partie repris aux périodes contemporaines. Aussi, la principale difficulté à prendre en compte dans une prospection focalisée sur une période d'exploitation concerne la discrimination chronologique des vestiges. C'est pourquoi cette deuxième partie débute par un point méthodologique avant de présenter les résultats.

\footnotetext{
${ }^{22}$ Il ne précise pas le lieu : «D'après M. de Cizancourt, on y aurait trouvé une monnaie (médaille) antique à $80 \mathrm{~m}$ de profondeur » (Daubrée 1868 , 268).

${ }^{23}[\ldots]$ erei $[\ldots / . .$.$] , T(iti) f(ilius) Pol(lia tribu), Titus [...]. AE 1986, { }^{\circ} 470$ (non vidi) : (Mantenant 2014, 338).

${ }^{24} \mathrm{AD} 34,8 \mathrm{~S} 139$.

${ }^{25}$ AD 34, 8S 171.

${ }^{26}$ AD 34, 8S 136 et 137.

${ }^{27}$ AD 34, 8S 142.

${ }^{28}$ AD 34, 8S 142
} 


\section{Méthodes suivies}

\section{Orientation générale}

La campagne 2016 s'est focalisée sur une étendue réduite, chaînée aux mentions médiévales, de Villemagne à La Roque et de Taussac à Clairac (fig. 5). Les mines de Boussagues ont également été recherchées. En revanche, la vallée de Lamalou n'a pas été retenue pour cette campagne. La mention des mines de la paroisse de Saint-Pierre de Rhède renvoyait en effet à un espace bien trop large et imprécis. Il pourra faire l'objet de compléments ultérieurs.

De cette façon, nous avons été en mesure de couvrir plus complètement l'espace métallifère induit par la carte géologique, et d'associer avec une plus forte probabilité les travaux anciens repérés aux exploitations des $\mathrm{XII}^{\mathrm{e}}$ et XIII ${ }^{\mathrm{e}}$ siècles, au moins en partie. Après une phase de dépouillement et de synthèse, l'objectif était donc pour cette opération d'homogénéiser et de compléter la documentation des sites déjà connus, tout en amplifiant les prospections entre et autour desdits sites. Nous avons enfin été particulièrement attentifs à la reconnaissance d'ateliers et de structures d'assistance.

\section{Pratique du terrain et enregistrement des vestiges}

D’une manière générale, les prospections s'effectuaient en ligne avec un espacement de 5 à $10 \mathrm{~m}$ entre chaque prospecteur. Les lignes sont tenues dans la mesure du possible, compte tenu de la végétation, très dense, qui posait constamment des problèmes de visibilité et de progression. Lorsqu'un vestige était atteint, ou reconnu, une prospection plus fine était organisée en rayonnant autour de lui. Puis la ligne était reprise ou adaptée en fonction des circonstances orographiques ou hydrauliques.

L'enregistrement des vestiges repose sur les principes du système d'information archéologique (SIA) SyslatTerminal, adapté ici pour la prospection (Py 2017). Le découpage du terrain en Zone conditionne la numérotation. Dix zones de prospections ont été définies au début de la campagne. Elles l'ont été en fonction de critères géographiques (versant d'une colline ; bassin d'un ruisseau...) et dans une moindre mesure géologique (faille, dyke...), favorisant une prospection homogène et envisageable en une journée. Au sein d'une zone, chaque vestige repéré a été enregistré comme un Fait archéologique. Les Faits les plus fréquents sont des haldes (HA), des chantiers d'exploitation $(\mathrm{CH})$, des structures (ST), des travers-bancs (TB), des puits (PU). Dans certains cas, plusieurs Faits s'associent dans un Ensemble fonctionnel. Tous les ensembles recensés pour le moment sont des exploitations (EXP) et regroupent généralement une halde à un chantier. Si le Fait à une uniquement une valeur descriptive, l'Ensemble à ici une valeur interprétative. Enfin, l'Entité archéologique a vocation de regrouper par commodité Faits et Ensembles dans des groupes fonctionnels ou techniques qui se distinguent topographiquement. Elle correspond dans notre optique à l'Entité archéologique de la base Patriarche (Chaillou, Thomas 2007). Sa dénomination dans Syslat est libre.
Pour rester cohérents avec les dénominations existantes, nous avons opté pour le toponyme IGN le plus proche, associé à un numéro, de 1 à $\mathrm{n}$.

\section{De la datation des vestiges}

La littérature et l'archéologie minière différencient traditionnellement les travaux dits « anciens » des travaux dits " modernes ». La rupture entre les deux intervient lorsque la poudre a été introduite dans les méthodes d'exploitation minières, soit dès la fin du $\mathrm{XVI}^{\mathrm{e}}$ siècle en Italie du Nord, au moins de façon ponctuelle, et à partir du début du $\mathrm{XVII}{ }^{\mathrm{e}}$ siècle de façon régulière (Vergani 1979, 2003). La date généralement retenue est 1617 pour les Vosges (Pierre 1992, 2015). En Languedoc pour le moment, l'usage de la poudre a été observé, ponctuellement, à partir de 1640 (Kammenthaler et al. 2016). Il faut toutefois prendre garde à ne pas interpréter ce basculement comme définitif, car la poudre met longtemps avant de s'imposer, et bien des travaux du $\mathrm{XVII}^{\mathrm{e}}$ siècle jusqu'au $\mathrm{XIX}^{\mathrm{e}}$ siècle utilisent encore des techniques manuelles.

Par conséquent, les problèmes de datation des travaux miniers sont récurrents lors de prospections voire de fouilles, car les techniques d'abattage « anciennes » pouvaient produire des ouvrages aux formes globalement comparables du Chalcolithique au début du XVII ${ }^{e}$ siècle (fig. 6). L'abattage par le feu est utilisé dans bien des cas, et les outils sont manuels. La difficulté vient aussi de la superposition des différentes périodes d'exploitations. Aussi, l'enregistrement d'exploitations sur une période ne veut pas dire que celle-ci serait exclusive.

Ces problèmes ne sont pas rédhibitoires, mais mettent en relief les difficultés rencontrées pour interpréter les données issues, en particulier, de prospection. Comme la campagne effectuée en 2016 s'est bornée à reconnaître les vestiges miniers en surface, leurs attributions chronologiques resteront très larges. Dans le cas d'un percement par l'outil et/ou le feu, l'ouvrage sera considéré comme un " travail ancien ». Dans le cas de l'utilisation de la poudre ou d'autres moyens mécanisés, l'ouvrage sera considéré comme un " travail moderne ». Enfin, dans les cas de superposition de ces techniques, l'ouvrage sera considéré comme un " travail diachronique ». Lorsque les ouvrages ne sont pas assez expressifs pour ce classement, nous avons préféré l'emploi des catégories « ancien probable », " moderne probable », « diachronique probable ». Enfin, lorsque l'on est en présence de travaux anciens, et s'ils se trouvent dans l'un des territoires médiévaux, au sein duquel des mines sont citées, alors nous supposerons que leur exploitation s'est probablement déroulée au Moyen Âge, du moins en partie. Cela n'exclut en rien la possibilité d'une exploitation partielle plus précoce ou de reprises plus tardives.

\section{Typologie descriptive des travaux}

Pour une meilleure cohérence du propos, nous organisons ici la description des vestiges par principaux types 


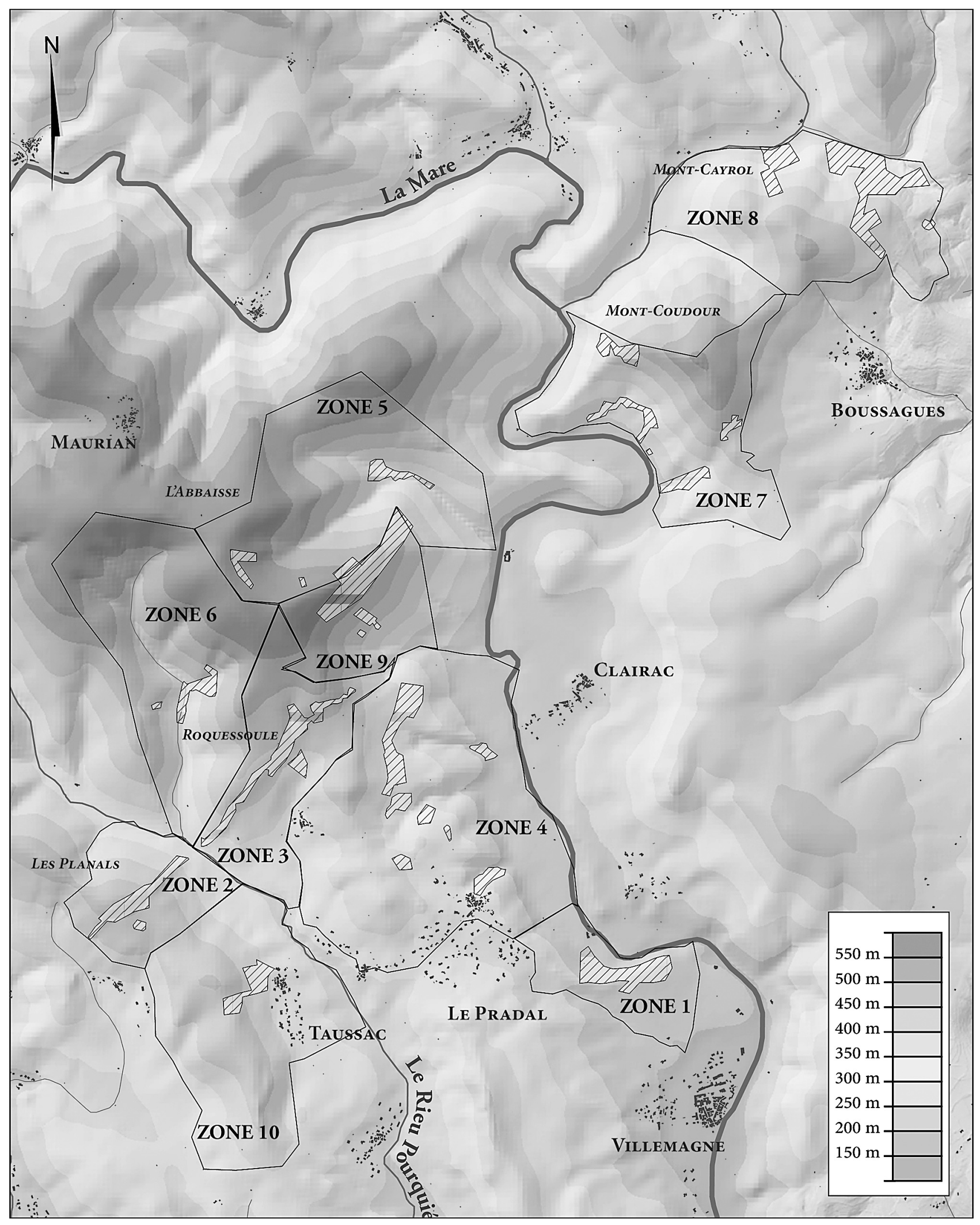

\begin{tabular}{|c|c|c|c|}
\hline $\begin{array}{c}\text { VILLEMAGNE } \\
\text { Zones et surfaces prospectées }\end{array}$ & Zones de prospection & & \\
\hline $\begin{array}{l}\text { BD Alti - IGN - } 5 \mathrm{~m} \\
\text { BD Carthage - IGN }\end{array}$ & Surfaces prospectées en 2016 & & \\
\hline $\begin{array}{l}\text { Rattachement : Lambert } 93 \\
\text { SIG/DAO : N. Minvielle }\end{array}$ & Bâti actuel (IGN - BD-PAR) & 0 & $1 \mathrm{~km}$ \\
\hline
\end{tabular}

Fig. 5 : Zones prospectées en 2016. 


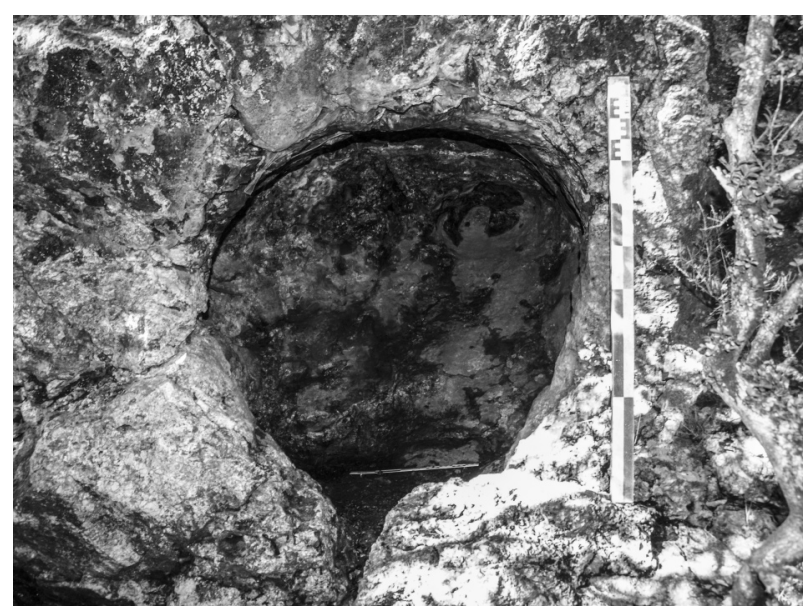

Fig. 6 : Planals-02, Chantier CH2009-a.

de gisement (fig. 7) (29). D'abord, viendront les gisements en partie stratiformes et karstiques contenus dans le substrat paléozoïque, soit le coteau de Cammal au Pradal et Taussac. Ensuite, les travaux répartis le long de la faille allant de Lamalou à Boussagues, marquant le contact entre le substrat paléozoïque et le bassin mésozoïque seront globalement examinés du sud-ouest vers le nord-est. On terminera par les travaux répartis le long de la faille allant de la Fontête au Mont-Coudour, encaissée dans le substrat paléozoïque, toujours du sud-ouest vers le nord-est.

\section{L'exploitation de gisements stratiformes - amas - filoniens}

Le coteau qui borde la Mare à l'ouest, sur lequel s'est assis le village du Pradal, laisse apparaître dans sa pente une large épaisseur géologique, en particulier le contact entre le socle rocheux paléozoïque de la Montagne Noire - ici des dolomies massives - et les formations sédimentaires mésozoïques du bassin de Bédarieux - ici une succession de grès, marnes et dolomies (fig. 8). C'est au contact Paléozoïque/Mésozoïque que des travaux anciens avaient été repérés par Henri Gonord, se développant sur plusieurs centaines de mètres le long du coteau à partir de Cammal (Gonord 1966, 103). L'extrémité sud-est du coteau correspond à la localisation du minier de Capmal, cité en 1233, voire des mines de l'alleu de Saint-Martin citées en 1210 (voir supra). Aussi, et malgré un terrain actuel boisé, les prospections se sont attachées à suivre ce contact le long du coteau, en explorant aussi l'espace situé entre la falaise et la route.

Leurs résultats ont été décevants, dans la mesure où la falaise semble avoir été récemment exploitée pour la pierre, ce qui a eu pour conséquence de la reculer vers l'ouest et de recouvrir une large partie de sa base par des déblais actuellement végétalisés. Si des travaux miniers subsistaient en surface, ils auraient ainsi été effacés en grande partie. Aucune entrée en puits ou en galerie n'a de surcroît été repérée, notamment en raison des déblais de la carrière. Malgré tout, quatre haldes minières ont été individualisées légèrement en contrebas (Cammal-01), ce qui suffit à confirmer l'exploitation de ce secteur. Leur composition, aperçue seulement en surface, contient majoritairement des rejets de gangues, quartz et baryte, ainsi que des cailloux dolomitiques (fig. 9). Quelques traces de minéralisations cuprifères ont été observées. Aucun élément de datation n'a cependant été remarqué. Leur forme et composition ne permet pas non plus d'émettre une hypothèse : une origine ancienne, moderne ou diachronique reste donc possible.

En poursuivant le long du coteau vers le nord-ouest se trouve la mine du Pradal (Pradal-01). Bien connue de la littérature géologique et minière (voir supra), elle s'ouvre également sur le contact Paléozoïque/ Mésozoïque. Sa partie supérieure a été rapidement visitée, sans étude, car cela dépassait les objectifs de la prospection (30). Les chantiers exploitent des faisceaux filoniens et de probables amas minéralisés en galène argentifère dans les dolomies cambriennes. La mine débute par une descenderie d'une trentaine de mètres située en contrebas du village du Pradal. Le premier niveau est au contact des dolomies cambriennes et du grès triasique. De grandes chambres orientées nord-sud et est-ouest sont larges de 3 à $8 \mathrm{~m}$ et de 5 à $10 \mathrm{~m}$ de haut. Un puits ouvert dans l'une de ces chambres, profond d'environ $25 \mathrm{~m}$, communiquerait avec un second étage sous-jacent, qui lui-même accèderait à un troisième étage qui, selon la tradition, pourrait atteindre le niveau de la Mare. Celui-ci peut correspondre à l'entrée d'une galerie bouchée près du pont de la route de Villemagne à Clairac (Gensanne 1779, t. 1, p. 277-278 ; Gonord 1966, 101-102). Henri Gonord signale son entrée dans le coteau en contrebas du Pradal ; elle pourrait se rattacher à l'une des galeries supérieures qui se dirigent effectivement dans cette direction. Les prospections menées sur une partie du coteau ont été négatives et sont restées limitées car la végétation était difficilement pénétrable et ne permettait pas une vision suffisante du terrain. En l'état des connaissances, la mine du Pradal est pourvue des réseaux miniers les plus importants de l'espace de Villemagne. La forme des chantiers, les traces d'outils et d'aménagements nous sont parvenues dans un remarquable état de conservation, si bien qu'elle mériterait une exploration et une étude archéologique exhaustive. Sa dynamique d'exploitation, vraisemblablement diachronique, devra être restituée au moyen de topographies numériques et de sondages réguliers. Dans l'hypothèse où des travaux antiques, voire antérieurs, se confirment, elle sera en outre un terrain privilégié pour observer l'évolution des techniques d'exploitation et de l'organisation du travail avec ses phases médiévales.

\footnotetext{
${ }^{29}$ La présentation analytique par Zone, Entitée archéologique et Fait est disponible dans le rapport d'opération. La présente typologie est une brève synthèse, nous renvoyons donc pour les détails et davantage de figures (plans de localisation, photos...) au rapport d'opération conservé au SRA Occitanie, à Montpellier (Minvielle Larousse 2016).

${ }^{30}$ Sa visite a été notamment effectuée en compagnie de Philippe Galant (SRA Occitanie) et de Michel Berbigé que nous remercions en cette occasion.
} 


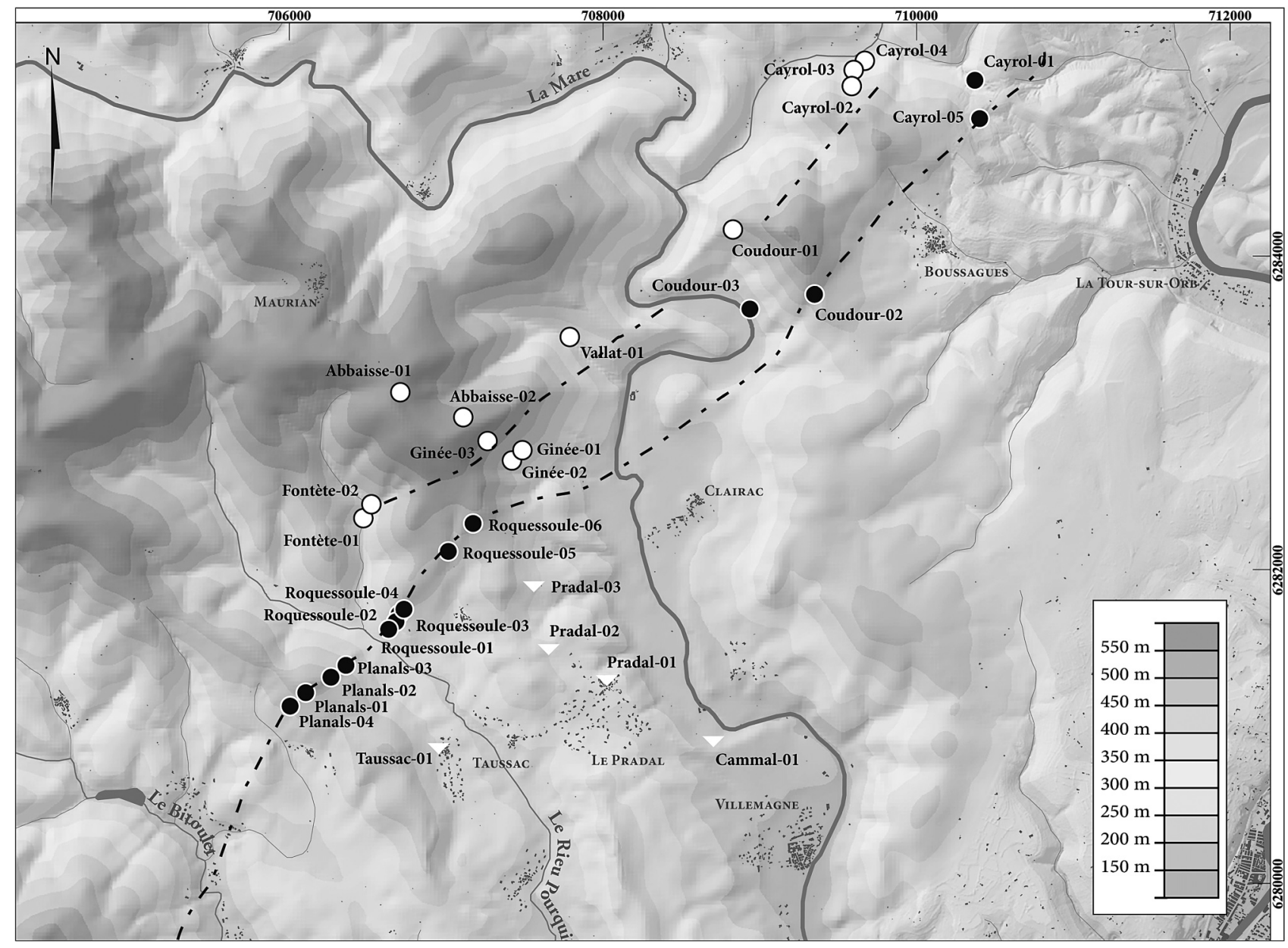

\begin{tabular}{|c|c|c|c|c|}
\hline $\begin{array}{c}\text { VILLEMAGNE } \\
\text { Localisation des mentions }\end{array}$ & $\nabla$ & Gisements contenus dans le substrat paléozoïque & & \\
\hline $\begin{array}{l}\text { BD Alti - IGN - } 5 \mathrm{~m} \\
\text { BD Carthage - IGN }\end{array}$ & & Gisements concentrés le long de la faille de Fontête/Coudour & & \\
\hline $\begin{array}{l}\text { Rattachement : Lambert } 93 \\
\text { SIG/DAO : N. Minvielle }\end{array}$ & -- & Failles de Fontête/Coudour (nord) ; de Lamalou/Boussagues (sud) & 0 & $1 \mathrm{~km}$ \\
\hline
\end{tabular}

Fig. 7 : Plan typologique des vestiges prospectés en 2016.

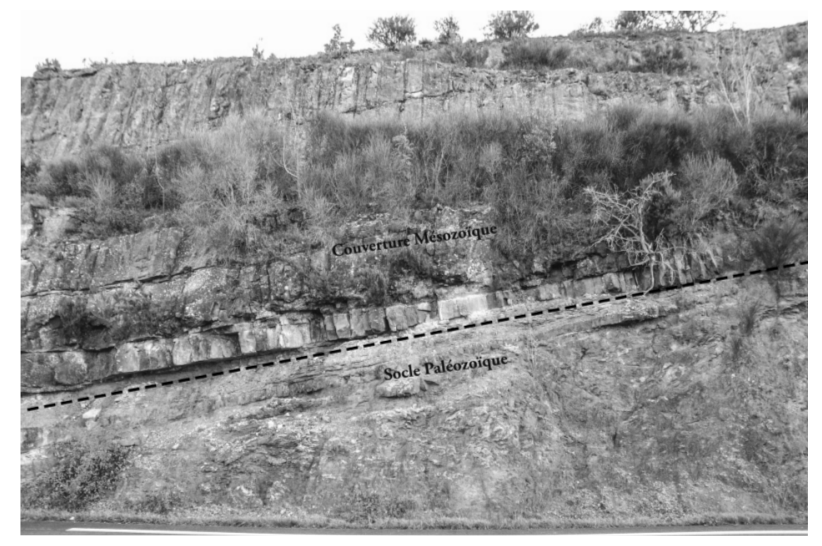

Fig. 8 : Cammal-01, vue du contact Paléozoïque/Mésozoïque.

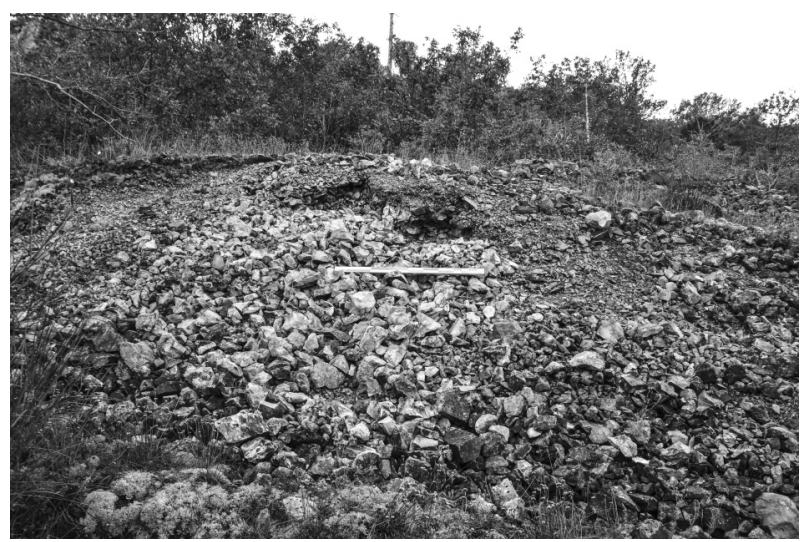

Fig. 9 : Cammal-01, vue d'une halde éventrée. 
L'exploitation du coteau s'était prolongée encore au nord-ouest, au-delà du Pradal, en se fixant notamment autour du ravin de Rouire et de son manse cité en 1233. La densité de la végétation n'a cette fois pas permis de prospecter ce secteur dans les temps impartis. Il le faudra ultérieurement, car le plan de la concession de 1864 (31) mentionne d'anciens travaux, et les indices rapportés par Henri Gonord (Gonord 1966, 105-106), semblent montrer que les reprises de la seconde moitié du $\mathrm{XIX}^{\mathrm{e}}$ siècle ne les ont pas tous recoupés ni détruits. Pour le moment, un seul vestige a été reconnu par Robert Guiraud et Robert Gourdiole : un départ de galerie à mipente qu'ils ont sondé à son ouverture. Si des niches à lampe étaient percées dans chacune de ses parois, et que les remplissages suggéraient deux phases d'exploitations, elle n'a pas encore été datée (Guiraud, Gourdiole 1978). Cette galerie est actuellement murée, si bien qu'il faudra trouver un autre point d'entrée vers ces travaux.

Enfin, une dernière mine a été exploitée sur ce même contact Paléozoïque/Mésozoïque, quoique dissociée de ce coteau. Il s'agit de celle de Taussac, située à $1,2 \mathrm{~km}$ au sud-ouest du Pradal (Taussac-01). Comme celle du Pradal, elle n'a été que visitée et mériterait de même une étude archéologique exhaustive. Même si son réseau paraît moins étendu, la forme de ses chantiers ainsi que les techniques d'abattage de la roche (feu et pic) y sont comparables. Le réseau, d'apparence labyrinthique, est fonction d'une gîtologie complexe pourvue manifestement de faisceaux filoniens et d'amas de minerai, dont l'exploitation a donné lieu à une succession de chambre de taille variable ainsi que d'un système de galeries et de puits permettant d'y accéder. Là aussi, sa chronologie n'est pas fixée. En dehors d'une phase médiévale, eu égard aux mentions de 1199 et 1233, il est possible qu'elle ait repris des travaux antérieurs.

\section{La faille de Lamalou / Boussagues}

Les deux tiers nord-est de la faille minéralisée allant de Lamalou à Boussagues ont été prospectés. Il s'agissait de parcourir les espaces suggérés par les mentions des mines de Taussac, des Bourdelles, de la Roque et, plus loin, de Boussagues. Cette faille sépare au nord-est les formations paléozoïques prés-cambriennes métamorphisées (zone axiale de la montagne Noire) des formations mésozoïques sédimentaires au sud-ouest, constituant le bassin de Bédarieux. Complexe, la faille a drainé diverses minéralisations sulfurées et oxydées au cours de ses périodes de formation et de rejeux (Gonord 1966 : 100). Les minéralisations polymétalliques se sont fixées sur les formations mésozoïques, ici une crête de dolomies hettangiennes, puissant marqueur du paysage mis en évidence par l'affaissement du bassin de Bédarieux (fig. 10). Cette crête apparaît en réalité de façon discontinue en surface, allant du sud-ouest vers le nord-est. Elle se matérialise par des portions de falaises irrégulières,

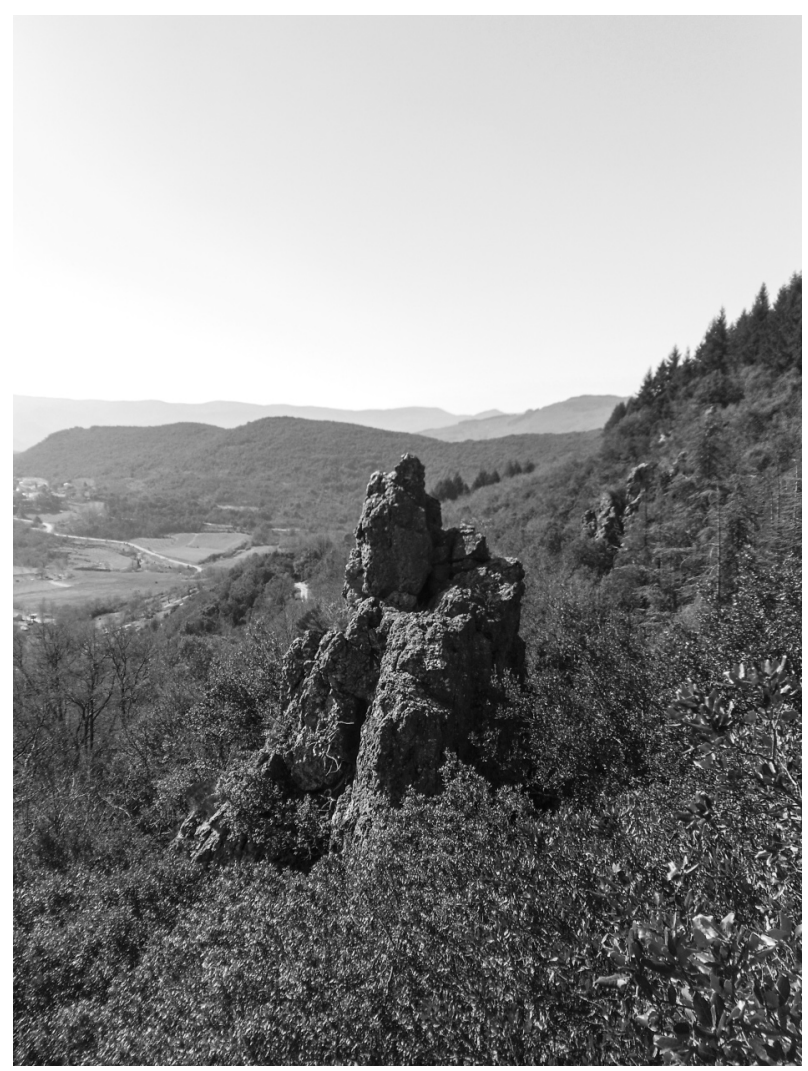

Fig. 10 : Crête dolomitique aux environs de Roquessoule.

longues de 10 à $50 \mathrm{~m}$, larges d'environ $10 \mathrm{~m}$ et hautes d'environ 5 à $10 \mathrm{~m}$. Chacune de ces falaises, ou presque, était minéralisée et a fait l'objet de chantier d'exploitation de taille variable ou de galeries de recherche.

Sur la colline des Planals, trois entités archéologiques ont été enregistrées (Planals-01-02-03-04). Passée la vallée du Rieu Pourquié, une seconde colline se développe vers le nord-est, nommée Roquessoule, sur laquelle se poursuit la crête de dolomie, toujours avec discontinuité. Sur celle-ci, six entités archéologiques ont été enregistrées (Roquessoule-01-02-03-04-05-06).

Tout au long de la crête, les travaux visibles sont hétérogènes, tant dans leur forme que dans leur développement. Sous réserve d'une étude gîtologique approfondie, les minerais exploités étaient surtout présents sous forme d'amas et, dans une moindre mesure, de modestes faisceaux filoniens. Pour les extraire, les ouvriers ont largement tiré profit des nombreuses fracturations de la crête, soit parce qu'elles mettaient au jour les minerais, soit parce qu'elles favorisaient le percement de galeries, voire directement de chantiers d'exploitation, lesquels prenaient in fine la forme des remplissages minéralisés.

Les ouvrages miniers se caractérisent donc d'abord par de modestes curages de parois, ainsi que l'on peut l'observer, par exemple, sur Roquessoule-04, ou par des

${ }^{31} \mathrm{AD} 34,8 \mathrm{~S} 142$. 
galeries de recherches percées en élargissant une faille préexistante, à l'instar de celle aperçue sur Planal-01. Elle l'a élargie à sa base sur 0,8 à $1 \mathrm{~m}$ de large et l'a prolongée, sur $7 \mathrm{~m}$ de long au moins, mais sans donner accès à un amas. En revanche, dès que les recherches étaient positives, l'exploitation des minerais débutait dans l'épaisseur de la crête. Il y a trois beaux exemples de chantiers de ce type, à Planal-01, Planal-02 et Roquessoule-01. Le premier s'ouvre d'ailleurs dans une faille et se développe sur 3,6 $\mathrm{m}$ de haut environ, $8 \mathrm{~m}$ de longueur et $2 \mathrm{~m}$ de largeur. Il est pourvu de deux entrées (sud-ouest et nordest) et d'un pilier central autour duquel rayonnent les fronts de taille (fig. 11). Le deuxième se compose dans son état actuel, de 4 excavations de 1 à 2,5 $\mathrm{m}$ de côtés, dont un porche de $4 \mathrm{~m}$ de long, $2 \mathrm{~m}$ de large et $2 \mathrm{~m}$ de haut creusé par le feu (fig. 12). Il donne accès à une courte galerie, elle-même menant à un puits descendant $(1,5$ mètre de profondeur environ), au fond duquel plusieurs départs de galeries sont visibles. La succession des ouvrages représente les amas successifs abattus par les mineurs, ainsi que les brefs accès ménagés entre chaque chantier. Le troisième enfin présente un développement plus large encore. L'intérieur de la crête a en effet été vidé du nord-est vers le sud-ouest par un chantier d'abattage subvertical (32), $a$ priori descendant (fig. 13), de 1,8 $\mathrm{m}$ de large en moyenne, d'environ $14 \mathrm{~m}$ de long et de $6 \mathrm{~m}$ de haut au maximum.

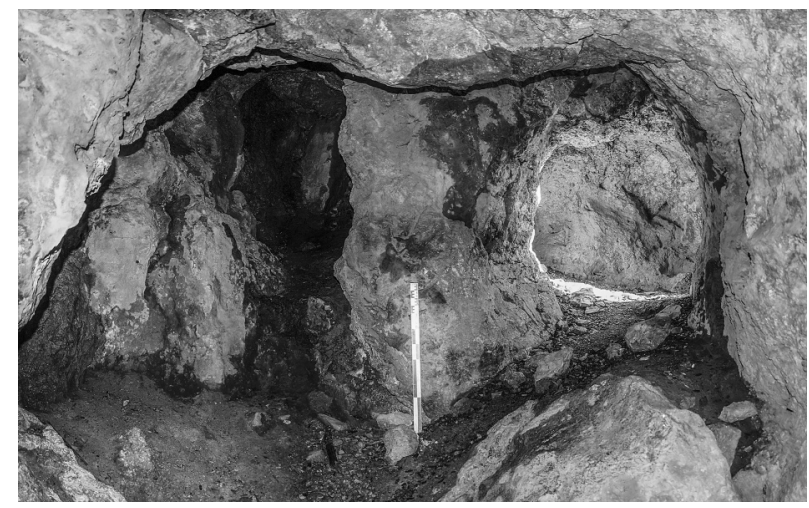

Fig. 11 : Planals-01, Chantier CH200.

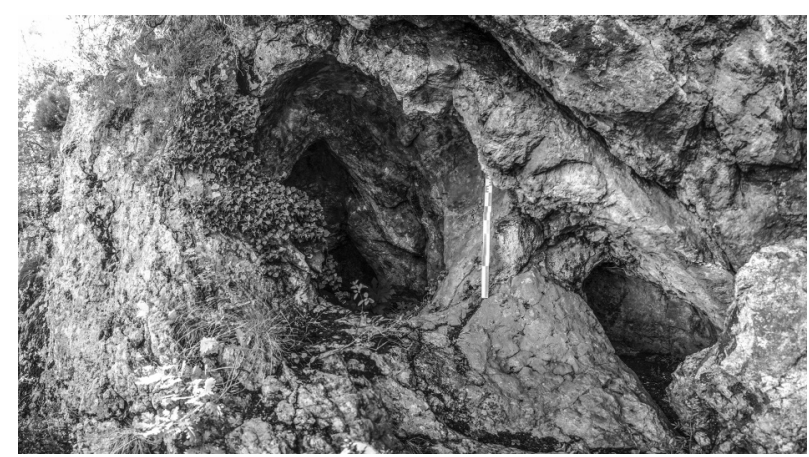

Fig. 12 : Planals-02, Chantier CH2009-b.

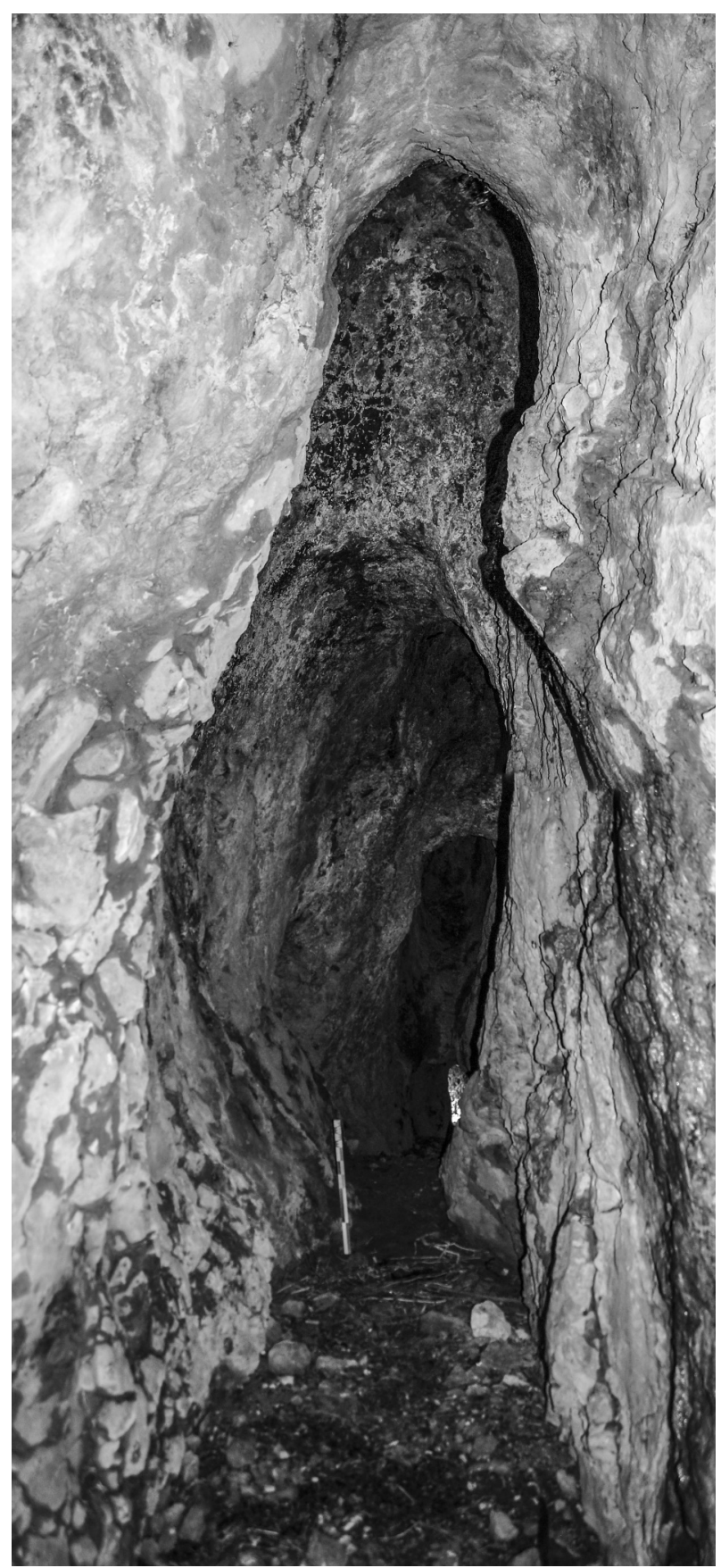

Fig. 13 : Roquessoule-01, Chantier CH3001.

Bien qu'il y ait une gradation dans l'ampleur de ces chantiers, il apparaît d'une façon générale que les travaux sont restés bien modestes en comparaison des grandes mines du Pradal et de Taussac (voir supra). Toutefois, la vision que nous avons de ces ouvrages pourrait être tronquée par des remblaiements contemporains ou postérieurs à leur fonctionnement. Il ne faut donc pas exclure des prolongements souterrains, comme le puits descendant du chantier de Planals-02 le suggère, et surtout dans la mesure où l'une de ces sections de crêtes a effectivement généré ce type de prolongement, à

${ }^{32}$ Terme employé communément dans l'appareil descriptif des ouvrages miniers, signifiant proche de la verticale. 
Planals-01. Le réseau n'a pas été exploré lors de cette campagne, car son entrée est fermée par une grille (33). Il s'agit néanmoins d'un vaste chantier d'exploitation souterrain s'ouvrant dans la crête dolomitique, comparable au moins sur sa morphologie et ses techniques d'abattage avec les mines du Pradal et de Taussac (34).

Que ce soit sur la colline des Planals ou de Roquessoule, les haldes sont très rares, tandis que les structures qui pourraient être associées aux travaux, s'il y en avait, sont restées dans l'ombre de nos prospections. En tout et pour tout, seules deux haldes ont été identifiées avec certitude à Planals-01. Elles sont d'ailleurs proches et séparées par de la végétation, si bien qu'elles n'en font peut-être qu'une, vraisemblablement en lien avec le chantier souterrain (fig. 14). Elles sont toutes deux partiellement recouvertes de végétation et de mousse et se composent de cailloux centimétriques de quartz, alliés à de rares cailloux de dolomie. Elles résultent de travaux d'extraction ou de minéralurgie. Cette dernière fonction est plus probable compte tenu des matériaux centimétriques plutôt calibrés qu'elles contiennent. Dans ce cas, il s'agirait de rejets d'un cassage, voire d'un concassage avancé du minerai.

Après Roquessoule, la falaise dolomitique marquant au jour la faille de Lamalou/Boussagues s'estompe. Il faut passer la Mare et poursuivre en direction du nord-est pour la retrouver sur les pentes méridionales du Mont-Coudour, une colline de la commune de la Tour-sur-Orbs, située 900 $\mathrm{m}$ à l'ouest de Boussagues (fig. 15). Sa prospection a été motivée par les mentions en 1189, 1199, 1201, 1263, 1271 de mines situées dans le mandement de Boussagues ( $a$ minima les Monts-Coudour et Cayrol). Le Mont-Coudour est constitué de plusieurs formations géologiques. C'est sa partie orientale qui chevauche la faille de Lamalou/ Boussagues. Ici, la faille s'intercale entre des dolomies et calcaires liasiques au sud-est et des schistes et dolomies cambriens au nord-ouest.

Des vestiges miniers se retrouvent à nouveau sur la crête dolomitique, à 400 mètres au sud-est du MontCoudour, sur la bordure occidentale du chemin menant

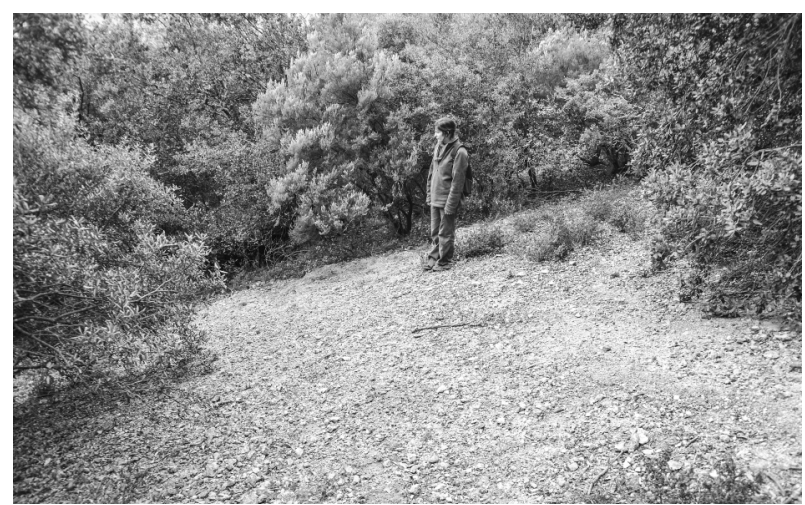

Fig. 14 : Planals-01, Halde HA2005.

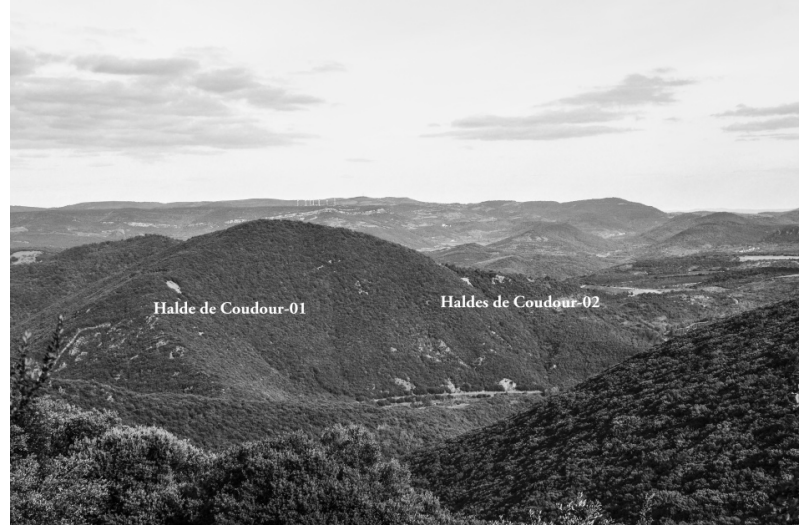

Fig. 15 : Vue générale du Mont-Coudour, haldes de Coudour01 (à gauche) et 02 (à droite).

au Cayrol. À Coudour-02, au moins trois petits chantiers similaires à ceux documentés sur les collines des Planals et de Roquessoule sont perceptibles. Toutefois, ces travaux sont indatables en l'état car des recherches et reprises contemporaines se sont concentrées dans le secteur. Elles pourraient expliquer la présence de quatre très vastes haldes en deçà de la crête, chacune se développant sur plusieurs centaines de $\mathrm{m}^{2}$ (respectivement $1016,1795,773$ et 1080). Toutes se composent majoritairement de dolomie, de schiste et de grès, ce qui les identifie comme des haldes extractives, dans la mesure où l'on se place au contact de ces roches (fig. 16). Aucune concentration de rejets minéralurgiques n'a été repérée.

À ce niveau de la faille de Lamalou/Boussagues et jusqu'à son extrémité du nord-est, les travaux anciens auraient ainsi été repris, ce qui rend les interprétations plus discutables et le potentiel archéologique, pour les périodes anciennes, moins assuré. Les mêmes interrogations s'appliquent aux rares autres vestiges reconnus à la base du Mont-Coudour (Coudour-03) ou sur les pentes du Cayrol (Cayrol-01 et 05).

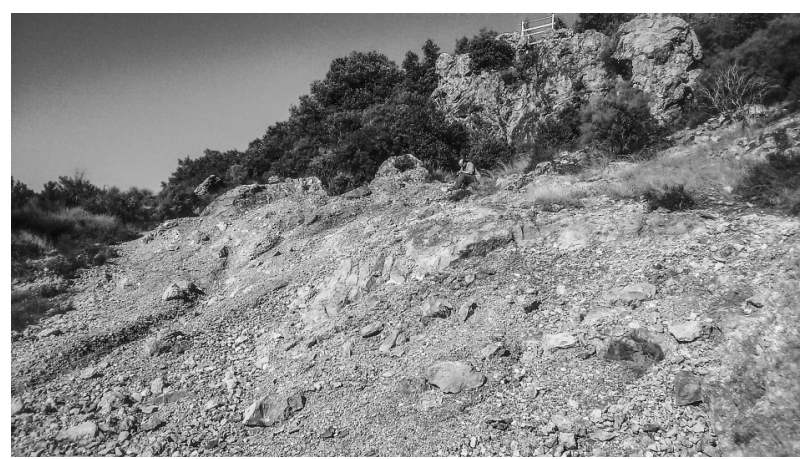

Fig. 16 : Coudour-02, Halde HA7008.

\footnotetext{
${ }^{33}$ Il est connu sous le nom de mine des Planals.

${ }^{34} \mathrm{D}$ 'après une information orale de Michel Savaire et de Philippe Galant que nous remercions.
} 


\section{La faille de Fontête / Coudour}

Une seconde faille se développe du sud-ouest vers le nord-est, parallèlement à la faille Lamalou/Boussagues. Elle débute au niveau du ravin de la Fontête au sud-ouest et s'achève sur les pentes septentrionales du Cayrol. Elle s'insère cette fois intégralement dans le socle paléozoïque de la zone axiale de la Montagne Noire, composée ici de formations schisto-gréseuses. Sa prospection était motivée par quelques mentions géologiques ou archéologiques de travaux anciens dans sa partie du sud-ouest (Gonord 1966, 119), et par les mentions textuelles relatives au castrum de Boussagues dans sa partie du nord-est, en particulier celles, en 1237 et 1289 , de plusieurs galeries Agrofolio, La poleia, La cleda et En Barata. Ces dernières se placent non loin d'un chemin allant vers l'Aire-Raymond (voir supra).

Dans le socle, les travaux miniers observés présentent de nettes différences avec ceux qui parsemaient les falaises dolomitiques. Des galeries ont majoritairement été inventoriées, soit issues de travaux de recherches, soit creusées en travers-banc. L'exemple le plus représentatif est assurément celle qui s'ouvre dans le lit du ravin de la Fontête, à l'extrémité sud-ouest de la faille (Fontête-02). Longue de $12 \mathrm{~m}$ au minimum, elle s'accompagne par une galerie inférieure et par un puits noyé (fig. 17). Selon une première hypothèse, il s'agirait d'une galerie de circulation horizontale (travers-banc) et verticale (puits) pouvant accéder à un chantier. A priori, le chantier n'est pas visible ici, sans doute est-il plus bas ou plus loin. Selon une seconde hypothèse, il s'agirait de galeries et puits de recherches, directement foncés dans le filon de quartz minéralisé en sphalérite et chalcopyrite (Gonord 1966, 118). En allant vers le nord-est, un deuxième exemple se trouve sur la colline de l'Abbaisse. Les vestiges de la mine de Lacan (Abbaise-01) se composent actuellement de plusieurs tranchées parallèles faites du sud-est vers le nord-ouest sur une longueur de plusieurs centaines de mètres, auxquelles s'ajoute au sud-est une galerie de recherche (Abbaisse-02) et des dizaines de haldes (Gonord 1966, 106 ; Béchiri 2001, 24-28). En l'état, aucun travail ancien ne se remarque, mais il faudrait une exploration approfondie, voire des sondages pour le déterminer. Les quelques vestiges situés en marge de la Fontête et de l'Abbaisse se rattachent à ces observations, qu'il s'agisse de galeries (Ginée-01-03, vallat-01) ou de haldes extractives (Fontête-01, Ginée-02).

Par-delà la Mare, la faille traverse enfin les schistes et les dolomies cambriens des Monts-Coudour et Cayrol. Comme leur partie occidentale est constituée uniquement de formations paléozoïques, les vestiges inventoriés sont aussi des ouvrages de circulation accompagnés de haldes extractives. Deux entités sont recensées : Coudour-01, et Cayrol-02. Il s'agit dans les deux cas d'ensembles composés de trois puits quadrangulaires de 1,5 à $2 \mathrm{~m}$ de côté foncés dans le socle et comblés au bout de quelques mètres. Ces puits peuvent avoir eu une fonction de recherche, de circulation ou encore d'aération. L'existence à Coudour-01 d'un petit chantier à ciel

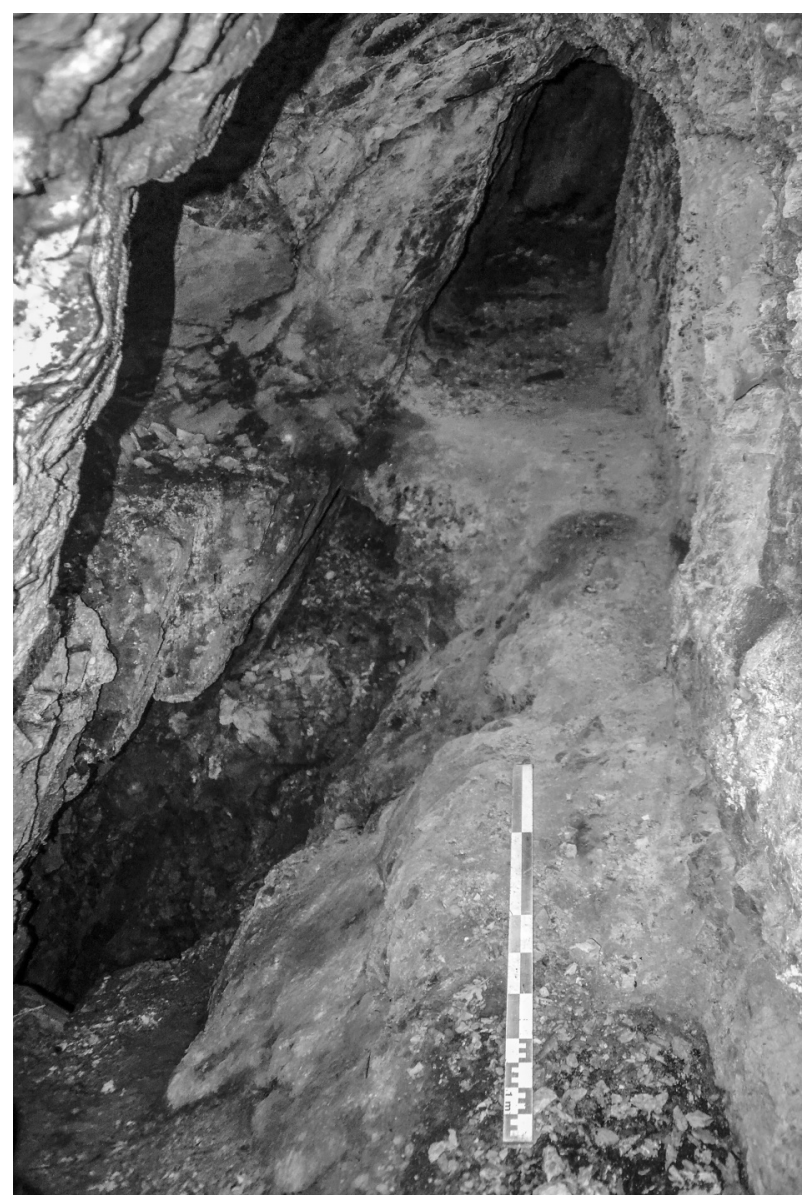

Fig. 17 : Fontête-02, Travers-banc TB6001.

ouvert à proximité du puits pourrait faire penser que des affleurements filoniens auraient été proches de la surface, mais aucun autre indice ne vient le corroborer. Les quatre haldes qui se trouvent, dans les deux cas, en contre-bas sont certes vastes, mais très majoritairement constituées de schiste (fig. 18). Seule celle de Cayrol-02 comporte quelques blocs de baryte et de quartz, mais sans présenter de concentration. Signalons pour terminer la présence d'une petite structure quadrangulaire de $2 \mathrm{~m}$ environ de côté à Cayrol-02, installée contre un affleurement rocheux, entre les deux puits en amont, et la halde

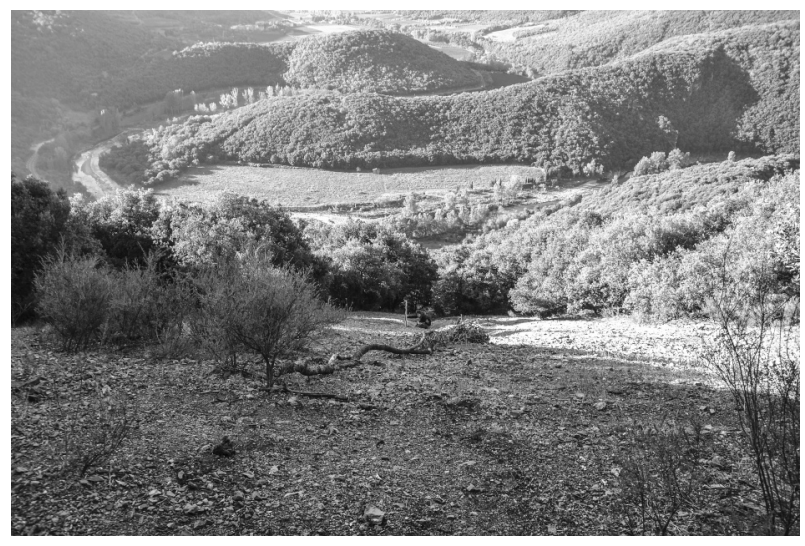

Fig. 18 : Coudour-01, Halde HA7001. 
en aval. La structure est construite avec des blocs issus de l'extraction (baryte notamment), mis en œuvre brut. Sa position, entre ces vestiges miniers, pose la question de son lien avec l'exploitation. Peut-être un bâtiment de stockage, il serait a priori trop réduit pour constituer un habitat temporaire ou un atelier. Cela étant, il peut tout aussi bien être postérieur et relié aux quelques rares murettes de culture disposées aux environs.

En somme, les travaux répartis le long de la seconde faille allant de la Fontête au Mont-Coudour sont, d'une part, inscrits dans une exploitation diachronique, et représentent d'autre part la partie visible de réseaux miniers plus étendus. Le fait que d'autres haldes plus diffuses soient réparties sur les pentes septentrionales de la colline, cela sans être associées à des ouvrages au jour (Cayrol-03-04), montrerait une exploitation en étage de ce versant. Les chantiers restent donc à découvrir.

\section{Bilan archéologique}

\section{Apports de la campagne 2016}

Dans le cadre proposé par les textes, nous avons été amenés à prospecter trois types de formations et de gisements.

Primo, des minéralisations en amas et en filon qui affleurent aux contacts de la dolomie cambrienne et des grès/dolomies triasiques (zones 1, 4 et 10). Les travaux se sont, d'une part, implantés entre Cammal et le Pradal et jusqu'au ravin de Roire au nord, sur la pente du coteau, avec dans un cas au moins un large développement souterrain dans les dolomies cambriennes. D'autre part, une même configuration se retrouve à Taussac avec le cas plus ponctuel d'un vaste chantier souterrain s'ouvrant également dans un affleurement de dolomies cambriennes.

Secundo, des minéralisations en amas et en filon situées le long de la faille de Lamalou/Boussagues, concentrées dans la crête discontinue de dolomies triasiques (zones 2, 3 et 7 dans une moindre mesure). Les chantiers s'ouvrent d'abord à ciel ouvert puis se développent dans l'épaisseur de la crête. Certains enfin se prolongent en souterrain en restant a priori dans le Trias.

Tertio, des minéralisations filoniennes situées sur et autour d'une faille parallèle, débutant dans le ravin de la Fontète, et s'étirant jusqu'au Cayrol à Boussagues (zones 5, 6, 7, 8 et 9). Les travaux se trouvent majoritairement dans les schistes, sauf la mine de Lacan qui a exploité, au-delà de cette faille, des filons contenus dans des dolomies cambriennes.

Les vestiges des travaux anciens se remarquent uniquement dans les deux premiers cas (fig. 19). Les reprises et recherches contemporaines semblent peu nombreuses sur ces terrains et, majoritairement, peu étendues. Seul Coudour-02 a été repris plus largement. En revanche, aucun indice très significatif n'a été décelé sur la faille parallèle Fontète/Coudours. Soit les travaux anciens étaient très peu étendus en raison du peu de visibilités des filons en surface, soit ils ont été allongés et recouverts par les reprises contemporaines de sorte qu'actuellement ils sont invisibles en surface.

\section{Discussions}

Les anciens ont visiblement eu une approche raisonnée et systématique du terrain. Les nombreux travaux répertoriés le long de la faille Lamalou/ Boussagues montrent qu'ils l'avaient prospectée et exploitée de façon exhaustive. Chaque faille a été testée, chaque amas a été vidé, même le plus résiduel. À aucun moment, nous n'avons remarqué des minéralisations encore en place hormis quelques incrustations stériles sur les parois des travaux. Ce même systématisme semble avoir été de rigueur au contact Cambrien/Trias, même si ce n'est pas encore aussi net. Les haldes réparties le long de la falaise à Cammal, la mine du Pradal, les mentions de travaux jusqu'à Roire suggèrent des tentatives suivies pour tirer profit des opportunités. À Taussac la démarche reste à confirmer. Cependant, il faudra corroborer cette vision en caractérisant mieux les ouvrages, certains sont encore difficilement interprétables, et surtout en les datant afin de différencier ce qui a pu être effectivement issu de travaux continus, de ce qui a éventuellement pu être issu de «cueillettes » plus diachroniques et ponctuelles.

À Boussagues sur les monts Coudour et Cayrol, des interrogations subsistent. Le versant sud-ouest du mont Coudour a été repris par la Société Vieille Montagne entre 1884 et 1959 (voir supra). Ces travaux sont restés ponctuels, mais suffisamment suivis pour complexifier les vestiges des exploitations. Un point d'accroche se trouve sur Coudour-02, où quelques vestiges de travaux anciens semblent subsister sur une partie de la crête dolomitique. Autrement, il nous est impossible de préciser le contexte de Coudour-01. Quant au versant septentrional du Cayrol, le problème est identique : des travaux anciens sont possibles et des reprises contemporaines probables. Or, les vestiges repérés ne permettent pas pour le moment de les identifier.

Nous n'avons pas été en mesure de relever de structures d'assistance, un de nos objectifs initiaux. Les prospections étaient plus larges que le seul suivi des terrains minéralisés, précisément dans ce but. Malgré cela, et le repérage de plusieurs haldes qui paraissent minéralurgiques, force est de constater que ces éléments manquent. Plusieurs raisons peuvent l'expliquer. D'abord sur les conditions de prospection : végétation prégnante, visibilité parfois très réduite, surface prospectée encore insuffisamment large. Ensuite sur le caractère des vestiges : ruine ou sédimentation trop avancée, structures en bois ou précaires, destructions postérieures. Enfin sur l'organisation même de la production : le traitement du minerai pouvait se concentrer dans quelques pôles à découvrir, plus éloignés des zones d'extraction.

\section{Synthèse des connaissances}

En rassemblant les données prospectées en 2016 avec celles inventoriées les décennies précédentes, cinquante entités archéologiques relatives à la production polymétallique ancienne peuvent être distinguées dans l'espace minier de Villemagne. La carte compile les données issues de prospections géologiques et archéologiques 


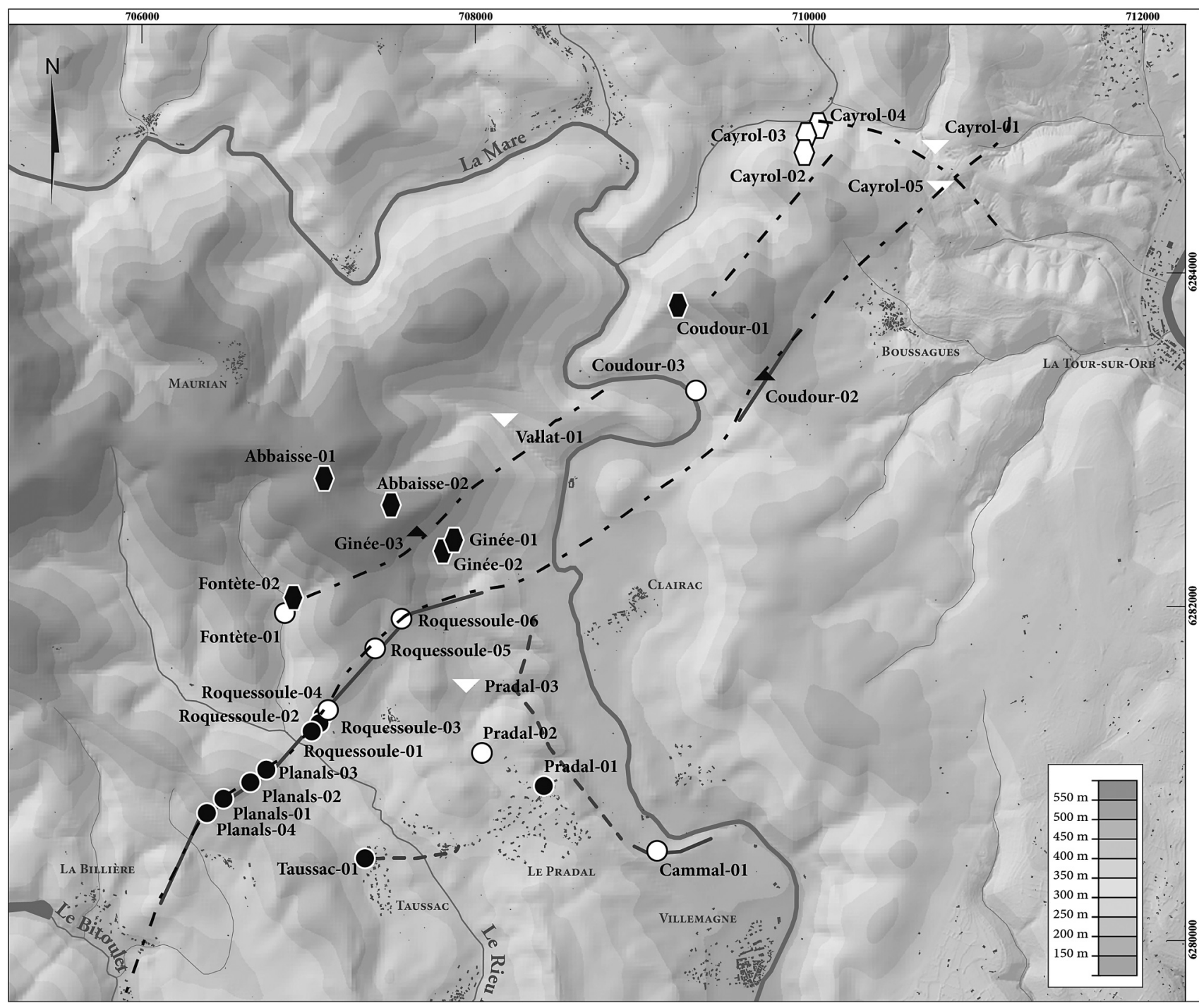

\begin{tabular}{|c|c|c|c|c|c|}
\hline Villemagne & Travaux anciens & & Travaux diachroniques & $--=$ & Principales failles \\
\hline Plan interprétatif & Travaux anciens probables & $\nabla$ & Travaux non datés & 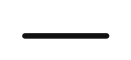 & Exploitation ancienne \\
\hline $\begin{array}{l}\text { BD Alti - IGN - } 5 \mathrm{~m} \\
\text { BD Carthage - IGN } \\
\text { Rattachement : Lambert } 93 \\
\text { SIG/DAO : N. Minvielle }\end{array}$ & $\begin{array}{l}\text { Travaux modernes } \\
\text { Travaux modernes probables }\end{array}$ & 0 & $2 \mathrm{~km}$ & -- & $\begin{array}{l}\text { Exploitation ancienne } \\
\text { supposée }\end{array}$ \\
\hline
\end{tabular}

Fig. 19 : Plan de synthèse des vestiges prospectés en 2016.

réalisées aux $\mathrm{XX}^{\circ}$ et $\mathrm{XXI}^{\mathrm{e}}$ siècles, ainsi que les mentions de travaux anciens portées sur les plans des ingénieurs des mines des $\mathrm{XIX}^{\mathrm{e}}$ et $\mathrm{XX}^{\mathrm{e}}$ siècles (fig. 20), tandis que le tableau lié présente de brèves analyses référencées (fig. 21) (35). En plus de la partie du nord-est de la faille de Lamalou/Boussagues, détaillée plus haut, il est probable que sa partie sud-est ait été exploitée tout aussi systématiquement.

\section{ESSAI D'ORGANISATION DE LA PRODUCTION ARGENTIFÈRE MÉDIÉVALE}

À partir de ces fondations, il est maintenant possible de proposer un premier bilan interprétatif. Fonction d'un état de la recherche, cet essai est surtout conçu pour stimuler la poursuite des investigations et pour initier des réflexions interdisciplinaires en croisant les données écrites, archéologiques et géologiques. Nous tenterons

\footnotetext{
${ }^{35}$ Les numéros BSS renvoient à la Banque du sous-sol, une archive gérée par le BRGM, consultable en ligne à partir d'Infoterre. Chaque fiche porte un numéro BSS qui l'identifie et permet de la retrouver en ligne. Les coordonnées Lambert de chaque entité archéologique sont disponibles dans le rapport d'opération déposé au SRA Occitanie, à Montpellier (Minvielle Larousse 2016).
} 
d'abord de fixer la répartition spatiale des principales étapes de la production médiévale, avant de les articuler avec la répartition des droits seigneuriaux tels qu'ils ont été fixés dans un large accord en 1233.

\section{Les étapes de la production}

La confrontation du territoire de 1164 , des divers toponymes des $\mathrm{XII}^{\mathrm{e}}-\mathrm{XIII}{ }^{\mathrm{e}}$ siècles avec les travaux anciens connus est significative (fig. 22). Le périmètre de 1164 est en effet pleinement en adéquation avec la répartition des gîtes polymétalliques. Son excroissance sud-est, jusqu'au château de Faugères, pourrait s'expliquer par le choix d'un point de repère plus marquant que ne pouvait l'être la villa de Soumartre, ou par le rôle de son seigneur, nécessitant de l'inclure dans l'accord. Sa lacune au nord-est n'est qu'apparente. En effet, le ressort du château de Boussagues s'ajoute et englobe certainement l'ensemble du mont-Coudour.

L'extraction était intensive dans un triangle Planals/Cammal/Roire. Les côtés occidental et oriental du triangle sont particulièrement concernés. Ils ont fait l'objet de prospections systématiques et de travaux aussi étendus que possible. Le côté méridional du triangle concerné avec le filon allant de La Blaquière à Taussac, dans une moindre mesure peut-être. Cet espace métallifère induit par les textes se confirme donc, et nous constatons $a$ fortiori, en ajoutant l'ensemble des sites inventoriés lors des diverses prospections, la forte corrélation entre les travaux anciens et les mentions médiévales.

$\mathrm{Au}$ nord, les travaux de Boussagues sont moins nombreux, mais se supposent au moins sur une section de la faille Lamalou/Boussagues. En dehors de cette présomption, nous ne pouvons pas encore localiser plus précisément les galeries d'Agrofolio, La poleia, La cleda et En Barata. Elles peuvent tout aussi bien se trouver au nord-est (Cayrol-01) qu'au sud-ouest de l'AireRaymond (Coudour 01 et 02), voire encore au nord-ouest (Cayrol 02). Elles sont cependant proches d'un ruisseau nommé la Poleia. Avec ce critère, Cayrol-01 se distingue, Coudour-01, et 02 s'éloignent, Cayrol-02 reste envisageable. Ce dernier serait par ailleurs plus conforme avec les concessions de 1237 et 1289 qui supposent la présence de plusieurs galeries proches. La question reste ouverte.

$\mathrm{Au}$ sud, entre l'Horte et Saint-Pierre de Rhèdes, même si nous disposons encore que de peu de données en raison de son exclusion des prospections de 2016 d'une part, et du manque de textes d'autre part, les activités paraissent aussi suivies que sur la partie septentrionale de la faille de Lamalou/Boussagues. Un troisième espace extractif était donc présent dans la vallée de Lamalou qu'il faudra à l'avenir mieux caractériser en prolongeant les prospections de Béatrice Béchiri.

D'autres mentions enfin sont plus éloignées des vestiges référencés. Clairac et Bédarieux sont problématiques. Aucun indice n'est pour le moment connu sur la rive gauche de la Mare. Quant aux mines des paroisses de Saint-Étienne de Dio et de Saint-André de Valquières, aucune prospection n'a encore été organisée pour les rechercher.
S'agissant du traitement du minerai, aucune donnée archéologique significative n'est pour le moment connue. Il y a bien les scories et céramiques ramassées il y a plusieurs années sur les bords du ravin de Roire, mais la visite de 2016 s'est révélée négative et il sera probablement bien difficile de suivre cette piste sans faire reculer la forêt. En regardant les textes, des ateliers ou des forges (fabrica) sont signalés en 1233 à Taussac, mais sans plus de précisions. En revanche, les concessions de 1237 et 1289 pour En Barata à Boussagues offraient la possibilité aux exploitants de construire des structures d'assistance (domum ad opus communitatis balme) des ateliers ou forges (fabrica), de possibles bassins de lavage (naucos) et des canaux d'amenée d'eau. Cela reste toutefois une potentialité, rien d'autre d'indique que les exploitants les aient effectivement construits. En fait, à bien considérer la répartition des pôles de peuplement, peu ou prou identiques à nos jours, il est probable que le traitement du minerai, donc la plupart des structures d'assistance, se situe dans les hameaux. L'hypothèse repose sur deux arguments.

D'abord, les travaux se succèdent le long des contacts en de multiples chantier ou recherches de petite ampleur. Aucun d'eux ne paraît actuellement suffisamment ample pour justifier l'établissement d'un quartier de traitement à proximité. Du reste, lorsque les réseaux sont plus importants, en particulier à Taussac et au Pradal, ils se trouvent déjà dans un lieu habité. La mine des Planals (Planals-01) fait toutefois exception.

Ensuite, la distance est faible entre les lieux d'extraction et les habitats. Le kilomètre n'est jamais dépassé, si bien que le tissu d'habitat existant pouvait suffire à prendre en charge le traitement du minerai et l'assistance des mineurs.

Ainsi, après l'extraction et un cassage/concassage effectués dans les réseaux de même qu'à proximité directe des gisements, le mélange mixte pouvait déjà être transporté pour achever son enrichissement. La question de la métallurgie reste quant à elle entière, car d'autres facteurs peuvent rentrer en compte (accès au bois, problème de la ventilation...). Si cette hypothèse se vérifie, cela signifie que les vestiges du traitement du minerai auraient été largement recoupés par l'évolution des habitats et en particulier l'extension de l'urbanisme que l'on note dans la seconde moitié du $\mathrm{XX}^{\mathrm{e}}$ siècle.

En conclusion, la production médiévale pourrait être organisée autour de 4 pôles : Le Pradal, Taussac, SaintMartin/Capmal et En Barata/Boussagues. Chacun d'entre eux est pourvu d'amples travaux miniers, d'un habitat permanent, de probables structures de traitement et d'assistance. Leurs mines paraissent suffisamment amples pour avoir fixé et fait perdurer l'activité pendant plusieurs dizaines d'années. À partir de ces points d'accroche, les exploitants auraient lancé des prospections systématiques sur les espaces métallifères alentour. Ces recherches se seraient traduites par la multiplication de petits chantiers qui auraient eu pour objectif d'explorer la moindre faille et de curer le moindre amas de quartz. N'étant pas suffisamment amples pour générer un processus de production complet, ils semblent être restés au rang de satellites de l'un ou de l'autre des pôles. 


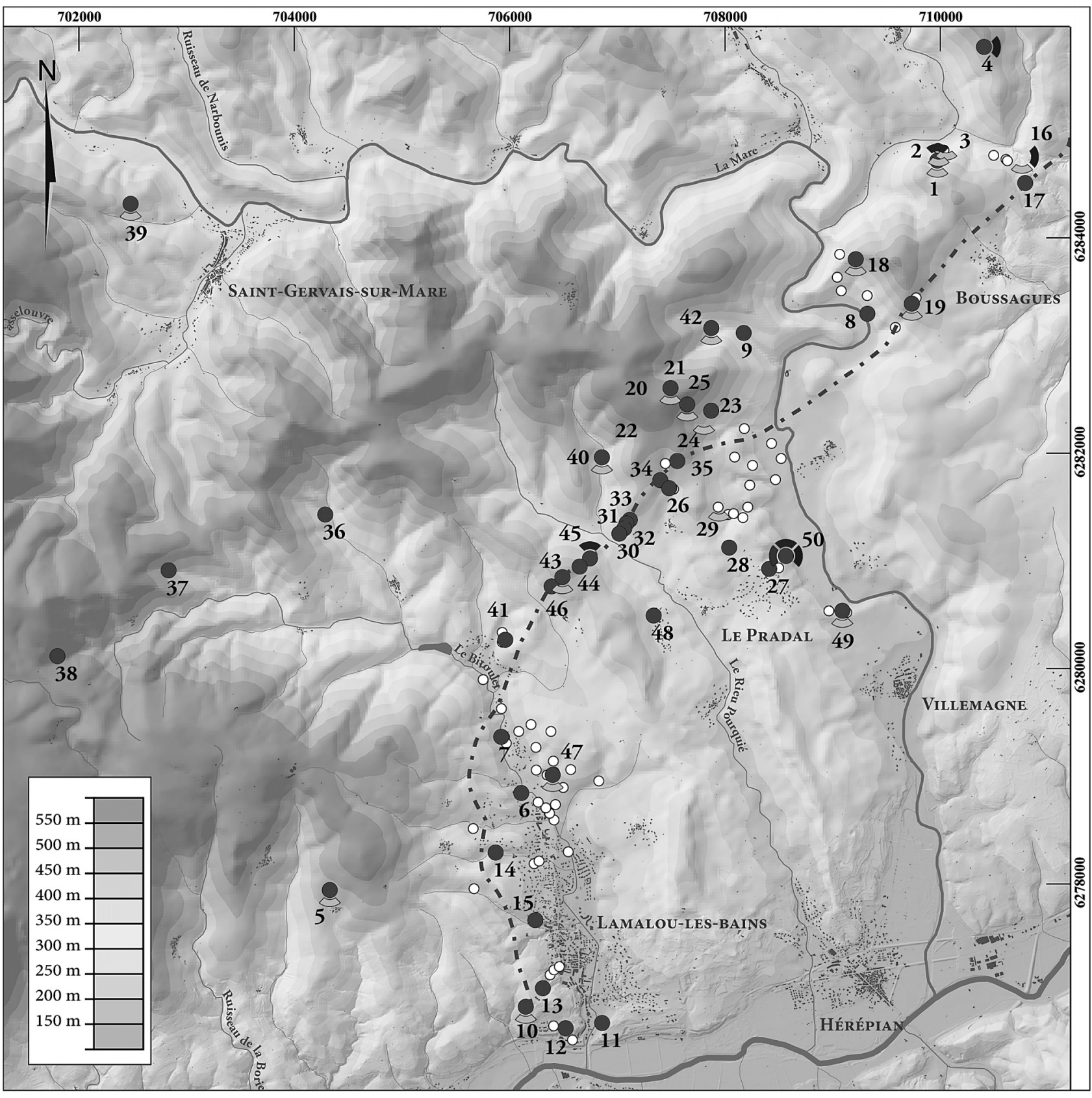

\begin{tabular}{|c|c|c|c|}
\hline $\begin{array}{c}\text { VILLEMAGNE } \\
\text { Localisation vestiges anciens }\end{array}$ & Structures d'assistance & $\begin{array}{l}\text { Travaux anciens } \\
\text { ou indéterminé }\end{array}$ & \\
\hline Localisation vestiges anciens & minéralurgiques métallurgiques & $\begin{array}{l}\text { - Plans de la faille de Lamalou- } \\
\text { Boussagues (Gonord } 1966, \text { Pl. XIX-XXI. }\end{array}$ & \\
\hline $\begin{array}{l}\text { BD Alti - IGN - } 5 \mathrm{~m} \\
\text { BD Carthage - IGN }\end{array}$ & Haldes & - $A D 34,8 S 142$ (concession de 1864). & \\
\hline $\begin{array}{l}\text { Rattachement : Lambert } 93 \\
\text { SIG/DAO : N. Minvielle }\end{array}$ & $\begin{array}{c}\text { Travaux anciens } \\
\text { Prospections R. Gourdiole; } \text { R. Filippo et al. ; B. Béchiri }\end{array}$ & $\begin{array}{l}\text { - - Faille de Lamalou/Boussagues } \\
\quad \text { Bâti actuel } \\
\text { BD parellaire 2016-IGN }\end{array}$ & $2 \mathrm{~km}$ \\
\hline
\end{tabular}

Fig. 20 : Synthèse des connaissances archéologiques.

\section{Une coseigneurie équilibrée?}

Pour achever cet essai, nous avons l'opportunité d'approcher de plus près la réalité de la coseigneurie partagée entre l'abbaye bénédictine de Villemagne, le seigneur de Boussagues et celui de Faugères, deux châtelains locaux. Les ressources minières qui s'y intégraient peuvent en effet apparaître, via les modalités de leur contrôle, comme un révélateur des rapports entre coseigneurs en même temps qu'un facteur explicatif de l'organisation de la coseigneurie (36).

Le 8 septembre 1233, l'abbé de Villemagne s'était entendu dans un large accord avec Déodat de

${ }^{36}$ Sur ces questions, se référer notamment au chapitre III de La Seigneurie Collective (Débax 2012, 137-242). 


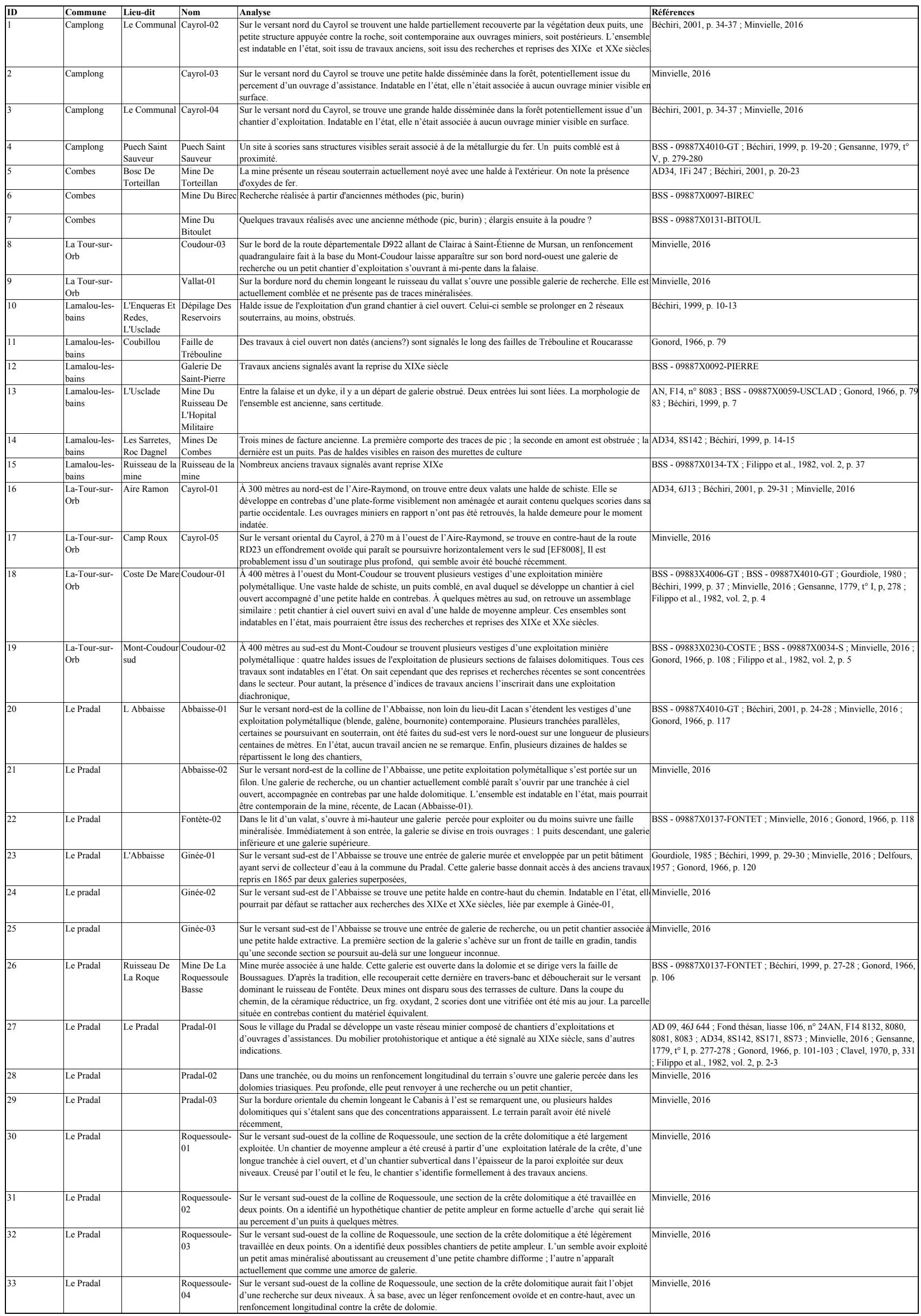




\begin{tabular}{|c|c|c|c|c|c|}
\hline 34 & Le Pradal & & \begin{tabular}{|l|} 
Roquessoule- \\
05
\end{tabular} & \begin{tabular}{|l|} 
Sur le versant sud-ouest de la colline de Roquessoule, une section de la crête dolomitique paraît avoir été \\
travaillée en trois points. Un premier chantier potentiel, creusé sur la paroi de la crête dolomitique ; un second \\
élargissant une faille sur quelques mètres de long ; un troisième comblé paraissant s'enfoncer sous la crête.
\end{tabular} & Minvielle, 2016 \\
\hline 35 & Le Pradal & & $\begin{array}{l}\text { Roquessoule- } \\
06\end{array}$ & $\begin{array}{l}\text { Sur le versant sud-ouest de la colline de Roquessoule, une section de la crête dolomitique a fait l'objet d'un } \\
\text { travail de recherche, voire d'une petite exploitation. }\end{array}$ & Minvielle, 2016 \\
\hline 36 & Rosis & & \begin{tabular}{|l} 
Mine De La \\
Bergerie De \\
La Billière
\end{tabular} & Travaux anciens signalés avant la reprise du XIXe siècle & BSS - 09886X0027-BERGER \\
\hline 37 & Rosis & Le Laux & Mine Du Lau & $\begin{array}{l}\text { Galerie comblée potentielle. Pas de halde associée ; mention de travaux aux pics dans les AD31. Traces de } \\
\text { fleurets }\end{array}$ & Béchiri, 1999, p. 21-22; Béchiri, 2001, p. 5-12 \\
\hline 38 & Rosis & La Rouviere & \begin{tabular}{|l} 
Mine Du \\
Ruisseau Du \\
Cros
\end{tabular} & $\begin{array}{l}\text { Mine de morphologie ancienne, verrouillée par une grille à cadenas. Elle débute par un grand travers-banc } \\
\text { d'accès pourvu de traverses de bois et de trous de fleurets. }\end{array}$ & Béchiri, 1999, p. 31 ; Béchiri, 2001, p. 13-19 \\
\hline 39 & Saint-Gervais & Le Navet & $\begin{array}{l}\text { Travaux Du } \\
\text { Doutou }\end{array}$ & \begin{tabular}{|l|} 
Anciens travaux effectués jusqu'à une trentaine de mètres du sommet, sur une longueur de $60 \mathrm{~m}$. Quatre \\
excavations, dont un grattage a existés, mais il ne reste plus que les tranchées d'accès, comblées par des éboulis \\
Pas de traces d'outils visibles, mais la morphologie des travaux est ancienne. Des haldes de petite granulométrii \\
sont contenues par des murettes de stérile déstructurée.
\end{tabular} & Béchiri, 1999, p. 2-3 \\
\hline 40 & $\begin{array}{l}\text { Taussac-la- } \\
\text { Billière }\end{array}$ & \begin{tabular}{|l} 
Ruisseau De \\
La Fontete
\end{tabular} & Fontète-01 & $\begin{array}{l}\text { Ȧ quelques mètres au nord-est de la première épingle du chemin remontant le valat de la Fontète s'ouvre une } \\
\text { petite galerie de recherche ou un petit chantier d'exploitation d'une longueur inconnue dont l'ouverture est au } \\
3 / 4 \text { comblée. Elle semble s'accompagner d'une petite halde placée inhabituellement en contre-haut de } \\
\text { l'ouvrage. }\end{array}$ & $\begin{array}{l}\text { BSS - 09887X0137-FONTET ; Béchiri, 1999, p. 17-18; Minvielle, } \\
\text { 2016; Delfours, 1957, p. 57 ; Gonord, 1966, p. } 118\end{array}$ \\
\hline 41 & \begin{tabular}{|l|} 
Taussac-la- \\
Billière
\end{tabular} & L'Horte & L'Horte & $\begin{array}{l}\text { Des déblais modernes masquent partiellement quelques travaux anciens dont la tradition fait remonter au } \\
\text { Moyen Âge. }\end{array}$ & $\begin{array}{l}\text { BSS - 09887X0124-TXGonord, 1966, p. } 110 \text {; Filippo et al., 1982, vol. } \\
\text { 2, p. } 46\end{array}$ \\
\hline 42 & \begin{tabular}{|l|l|} 
Taussac-la- \\
Billière
\end{tabular} & Les Prades & $\begin{array}{l}\text { Mine du Ravin } \\
\text { du Vallat }\end{array}$ & Mine d'apparence ancienne & BSS - 09887X0136-VALAT; Gonord, 1966, p. 119 \\
\hline 43 & \begin{tabular}{|l} 
Taussac-la- \\
Billière
\end{tabular} & Planas & Planals-01 & $\begin{array}{l}\text { Sur le versant sud-ouest de la colline des Planals, une section de la crête dolomitique a été exploitée en } \\
\text { plusieurs points. On a identifié des travaux de recherches, un chantier de petite ampleur, un chantier de } \\
\text { moyenne ampleur et un chantier de grande ampleur. Deux petites haldes minéralurgiques se développent à } \\
\text { quelques mètres. }\end{array}$ & Minvielle, 2016; Gonord, 1966, p. 109-110 \\
\hline 44 & $\begin{array}{l}\text { Taussac-la- } \\
\text { Billière }\end{array}$ & & Planals-02 & $\begin{array}{l}\text { Sur le versant sud-ouest de la colline des Planals, une section de la crête dolomitique a été travaillée en } \\
\text { plusieurs points. On a identifié une galerie de recherche ou un chantier de petite ampleur et un chantier de } \\
\text { moyenne ampleur creusés dans l'épaisseur de la crête sur } 3 \text { niveaux au moins, avec un prolongement souterrain } \\
\text { hypothétique. }\end{array}$ & Minvielle, 2016 \\
\hline 45 & $\begin{array}{l}\text { Taussac-la- } \\
\text { Billière }\end{array}$ & & Planals-03 & $\begin{array}{l}\text { Sur le versant nord-est de la colline des Planals, une section de la crête dolomitique a fait l'objet de deux } \\
\text { exploitations distinctes. Un travail de recherche, voire un chantier, de petite ampleur tout d'abord qui prend la } \\
\text { forme d'une chambre ovoïde que l'on aurait entièrement curée de ses minéralisations ; un chantier de moyenne } \\
\text { ampleur ensuite, creusé dans l'épaisseur de la crête dolomitique, et pourvu d'une galerie d'accès latérale. Une } \\
\text { plate-forme d'assistance semble enfin accompagner le chantier. }\end{array}$ & Minvielle, 2016 \\
\hline 46 & $\begin{array}{l}\text { Taussac-la- } \\
\text { Billière }\end{array}$ & & Planals-04 & $\begin{array}{l}\text { Sur le versant sud-ouest de la colline des Planals, une section de la crête dolomitique a fait l'objet d'une } \\
\text { exploitation, peut-être en élargissant une cavité karstique. Le chantier se remarque par son front de taille au seir } \\
\text { duquel } 2 \text { voire } 3 \text { coupoles d'abattage par le feu se distinguent. }\end{array}$ & Minvielle, 2016 \\
\hline 47 & $\begin{array}{l}\text { Taussac-la- } \\
\text { Billière }\end{array}$ & La Veyrasse & $\begin{array}{l}\text { Ruisseau des } \\
\text { Cambous }\end{array}$ & $\begin{array}{l}\text { Nombreux travaux antérieurs au XIXe siècle, dont une galerie bouchée et une citerne. Le filon dit du Moto-Cro } \\
\text { a été travaillé par les anciens en tranchées et galeries. Les travaux sont repérables par l'intermédiaire } \\
\text { d'importantes dépressions au sol. Les haldes associées paraissent copieuses. }\end{array}$ & Gonord, 1966, p. 76, 77 ; Filippo et al., 1982, vol. 2, p. 48 \\
\hline 48 & $\begin{array}{l}\text { Taussac-la- } \\
\text { Billière }\end{array}$ & & Taussac-01 & $\begin{array}{l}\text { A l'extrémité ouest du village du Pradal s'ouvre un vaste réseau minier composé de chantiers d'exploitations et } \\
\text { d'ouvrages d'assistances. Un puits descendant permet d'accéder à un réseau inférieur. Des puits remontant } \\
\text { aujourd'hui comblés pouvaient relier le premier étage à la surface. }\end{array}$ & $\begin{array}{l}\text { AD 09, 46J 644; Fond Thésan, liasse } 106, \mathrm{n}^{\circ} 14 \text { et } 26 \text {; Minvielle, } 2016 \\
\text {; Delfours, } 1957 \text {; Gonord, } 1966, \text { p. } 104\end{array}$ \\
\hline 49 & Villemagne & Cammal & Cammal-01 & $\begin{array}{l}\text { Entre Cammal et la route départementale 922, un coteau fait affleurer à la base de son versant nord un contact } \\
\text { entre les formations cambriennes (dolomie) et triasiques (gress, marne, dolomie). Ce contact paraît avoir été } \\
\text { exploite par les anciens sur une longueur de plusieurs dizaines de mètres. Aujourd hui comblées ou percées, les } \\
\text { exploitations ont pu générer les } 4 \text { haldes distinctes qui se succèdent à la base de la falaise. }\end{array}$ & $\begin{array}{l}\text { AD 09, 46J } 644 \text {; Fond thésan, liasse } 106, \mathrm{n}^{\circ} 24 \text {; Minvielle, } \\
\text { 2016Gonord, } 1966 \text {, p. 103-104; Filippo et al., 1982, vol. 2, p. } 51\end{array}$ \\
\hline 50 & Villemagne & $\begin{array}{l}\text { Grogues- } \\
\text { Hautes }\end{array}$ & \begin{tabular}{|l|} 
Zone Scorifềre \\
De Rouire
\end{tabular} & $\begin{array}{l}\text { Sur le flanc du coteau, une galerie a été désobstruée. Son entrée a été fouillée par Robert Guiraud et Robert } \\
\text { Gourdiole en 1978. En contrebas se trouve un site de traitement du minerai. Dans les vignes, un mobilier } \\
\text { nombreux et varié a été mis au jour : coulées de plomb, fragments de meule, fragments amphores, scories } \\
\text { vitrifíées de cuivre et de plomb, laitier de plomb, scories de fer, fragments de céramiques. Ces dernières sont } \\
\text { principalement médiévales et quelques-unes antiques. A A } 500 \mathrm{~m} \text { au sud, un autre site à scorie se développe } 500 \\
\text { m environ au sud où du charbon avec de la galène et du fer ont été ramassés. }\end{array}$ & $\begin{array}{l}\text { Gourdiole, } 1978 \text {; Béchiri, } 1999 \text {, p. 32-33; Gonord, 1966, p. 105-106; } \\
\text { Filippo et al., } 1982 \text {, vol. 2, p. } 8\end{array}$ \\
\hline
\end{tabular}

Fig. 21 : Tableau analytique des entités archéologiques.

Boussagues et Geoffroy de Faugères pour mettre un terme à plusieurs années de tensions (37). Celles-ci ont été provoquées d'une part par la politique d'acquisition foncière et minière des seigneurs de Boussagues, initiée en 1199 (38), et d'autre part par la pression renouvelée des seigneurs de Faugères. En effet, après un conflit péager en 1197, ceux-ci ont été destinataires de plusieurs droits et biens que possédaient les Trencavel dans le secteur, notamment leurs droits miniers en 1201 (39). La résolution du conflit, arbitré par des officiers royaux, concernait principalement l'exercice de la justice, la répartition et la levée de redevances dans plusieurs manses. Même s'ils ne sont pas majoritaires (10 articles sur 42), les articles concernant le partage du dominium minier permettent d'esquisser les contours de la coseigneurie telle qu'elle s'est stabilisée en 1233 (fig. 23).

Les coseigneurs se partageaient 4 types de redevances (fig. 24) : les parts de minerai, les justices et cautions, les oublies et foriscapes et les dîmes. Le minerai renvoie sans doute stricto sensu à la redevance pro dominio perçue en proportion de la production. Les justices, cautions, oublies et foriscapes sont des prélèvements induits par l'exercice du dominium. La dîme, enfin, était seulement perçue par l'abbaye, du moins dans ce qu'indique l'accord de 1233 .

Ces redevances étaient associées à 8 manses et à un minier, celui de Capmal. Toutes ne sont pas citées à chaque fois : manquent au Pradal et à Clairac, les oublies et les foriscapes ; la perception de la dîme n'est indiquée qu'au Pradal; enfin les revenus attachés au manse et au minier de Capmal ne sont pas détaillés. Ces lacunes induisent la présence possible d'autres coseigneurs. En effet, on retrouve peu ou prou les mêmes droits qui avaient été partagés entre les vicomtes de Béziers, de Narbonne, l'Abbaye de Villemagne, et d'autres seigneurs locaux non identifiés à l'occasion d'un accord

\footnotetext{
${ }^{37}$ AD 09, 46J 644 (Pasquier, Olive 1913, 76-94).

${ }^{38}$ La première occurrence de leur agrandissement est l'achat en juillet de l'ensemble des biens de Raimond Hugues situés dans le mandement de Boussagues et les paroisses de Clairac et Bédarieux : AD 09, 46J 644 (Pasquier, Olive 1913, 57-58).
}

${ }^{39} 1197$ : Sainte-Marthe 1739, col. 144, nº XX ; 1201 : Cartulaire des Trencavel, fo 224-224 vº nº 570 (Vic, Vaissète 1874, t. VIII, coll. 470-471, n 105). 


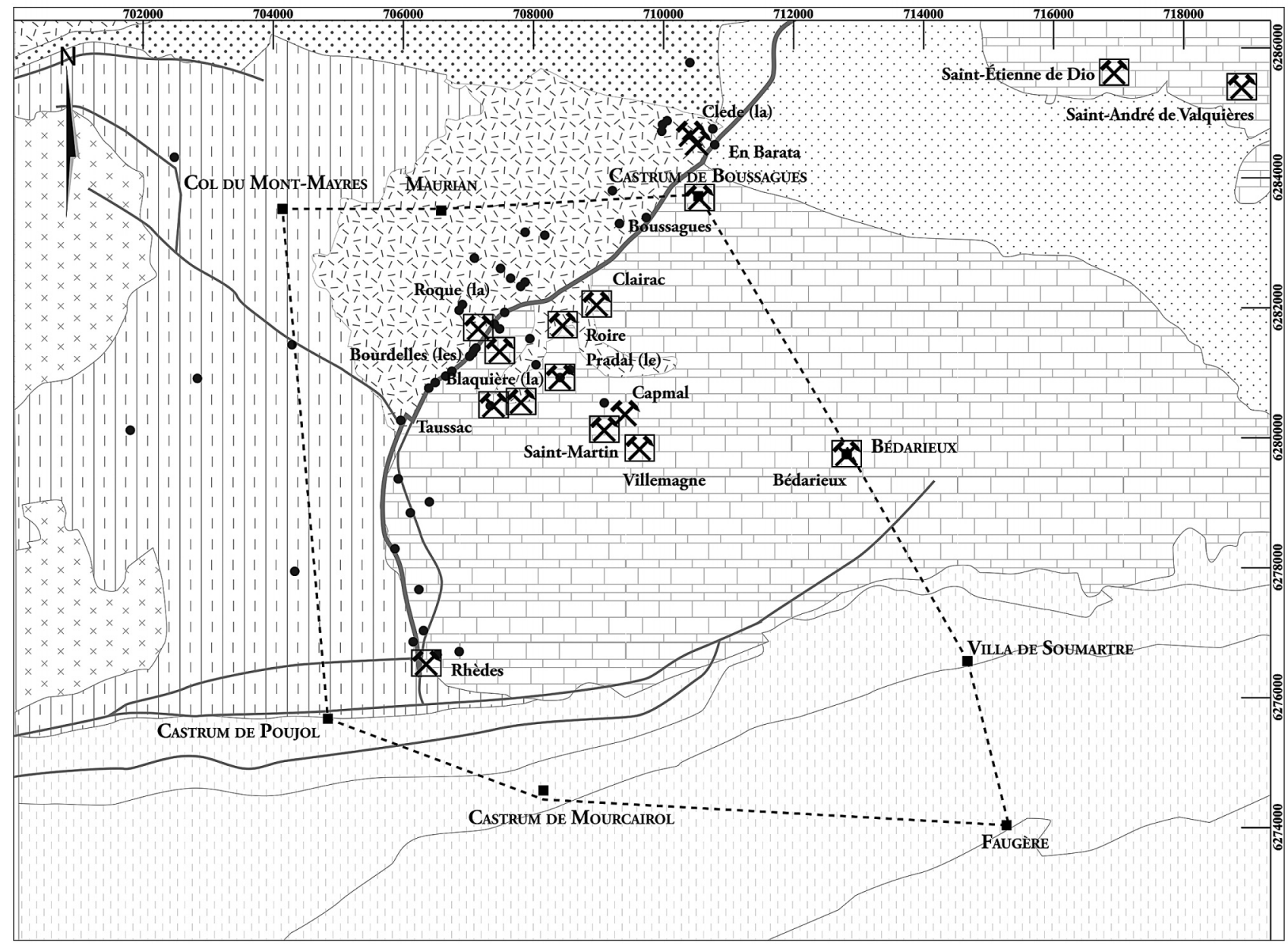

\begin{tabular}{|c|c|c|c|}
\hline $\begin{array}{c}\text { VILlemaGNE } \\
\text { Carte compilée } \\
\text { (Géologie, vestiges, mentions textuelles) }\end{array}$ & X & Mines comprises dans un territoire & $\begin{array}{l}\text { Sites miniers « anciens »(état 2016) : } \\
\text { l'inventaire et les sources sont supra. }\end{array}$ \\
\hline $\begin{array}{l}\text { D'après la carte géologique } \\
\text { harmonisée (BRGM) }\end{array}$ & $\ldots$ & Territoire défini en 1164 & $\begin{array}{l}\text { Légende du fond géologique : se référer à } \\
\text { la carte géologique, supra. }\end{array}$ \\
\hline $\begin{array}{l}\text { Rattachement : Lambert } 93 \\
\text { SIG/DAO : N. Minvielle }\end{array}$ & $\mathbf{\square}$ & Repère du territoire de 1164 & $4 \mathrm{~km}$ \\
\hline
\end{tabular}

Fig. 22 : Carte minière compilée (substrat géologique, vestiges archéologiques, mentions textuelles).

conclu en 1164 (40). La moitié de la redevance minière allait alors aux vicomtes, l'autre moitié aux seigneuries locales ; la totalité des mutations en revanche était réservée par moitié aux vicomtes. En 1233, le partage pouvait donc aussi bien concerner une seule moitié des revenus que la totalité, si les seigneurs locaux avaient entre temps récupéré la moitié vicomtale. Cette dernière hypothèse est plausible dans la mesure où l'accord devait durer 15 années, que nous n'avons pas trace d'un renouvellement et qu'il est question en 1233 des mutations, exclusivité des vicomtes en 1164. Du reste, nous savons que les droits miniers des Trencavel étaient passés après 1201 aux seigneurs de Faugères. Malgré ces éléments il faut rester prudent, car nous n'avons aucune donnée sur Narbonne. De plus, la question de la dîme demeure ; peut-être qu'une perception par l'évêque de Béziers est envisageable dans la mesure où il percevait celle de la paroisse de Saint-Pierre de Rhèdes jusqu'en 11821183 (41).

À première vue, le partage n'est pas à l'avantage de l'Abbaye de Villemagne. Certes exclusive à Capmal, elle ne détenait cependant la majorité des revenus qu'à Taussac. Ailleurs, elle devait se contenter du tiers, et aurait même été exclue du Pradal si elle ne percevait pas sa dîme. Or, à bien considérer la répartition à l'aune des données archéologiques, il est probable qu'au contraire le partage ménageait tous les coseigneurs. Nous savons que les principaux réseaux miniers se situaient au Pradal, à Taussac, et, dans une moindre mesure, à Capmal. Ces trois exploitations étaient suffisamment amples pour

\footnotetext{
${ }^{40}$ Se référer au commentaire établi par Claudie Amado : Amado 1977.

${ }^{41}$ BNF, Doat 61, fo 296 (Rouquette 1918, 403-405, n CCLXXXV).
} 


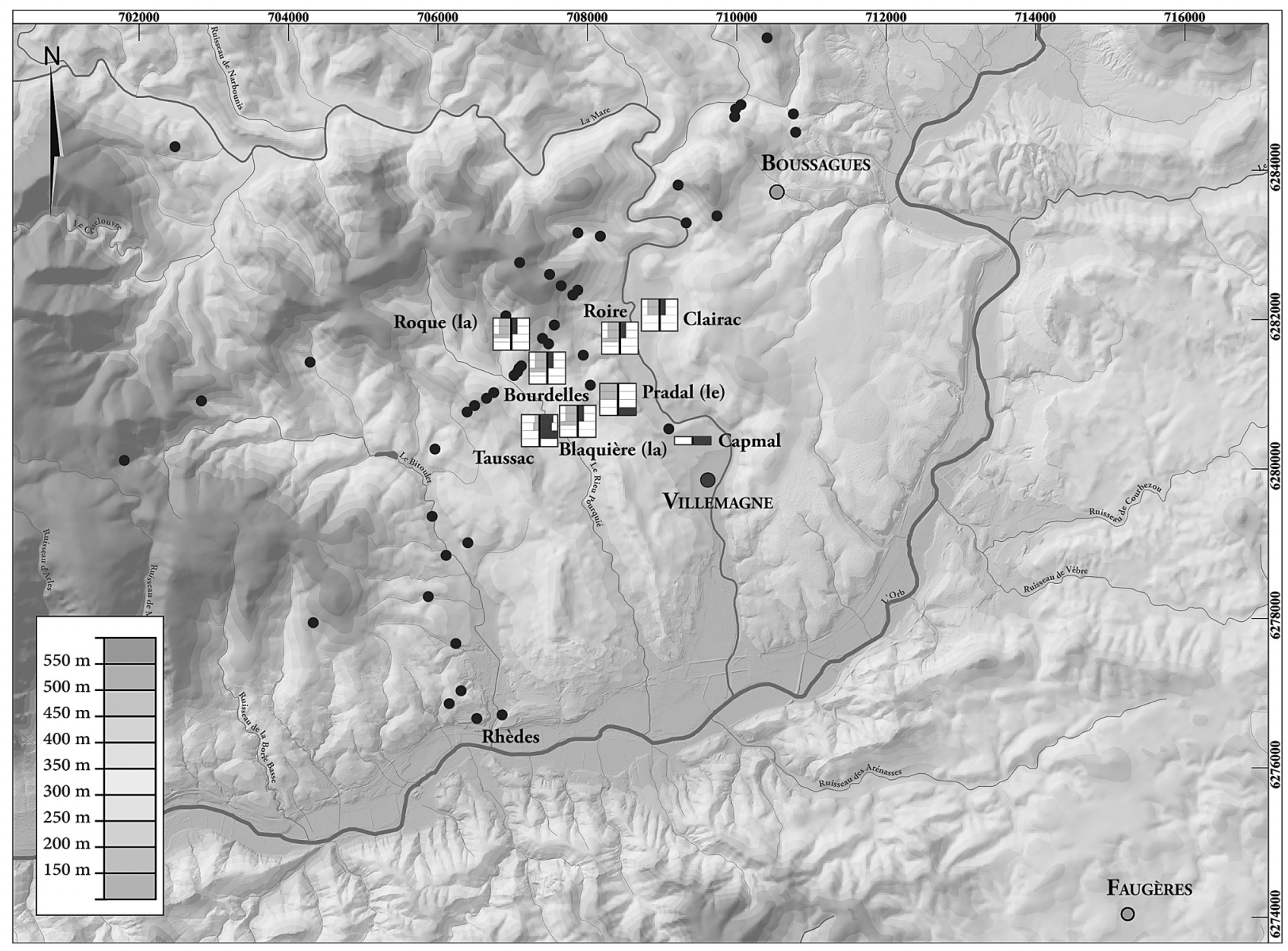

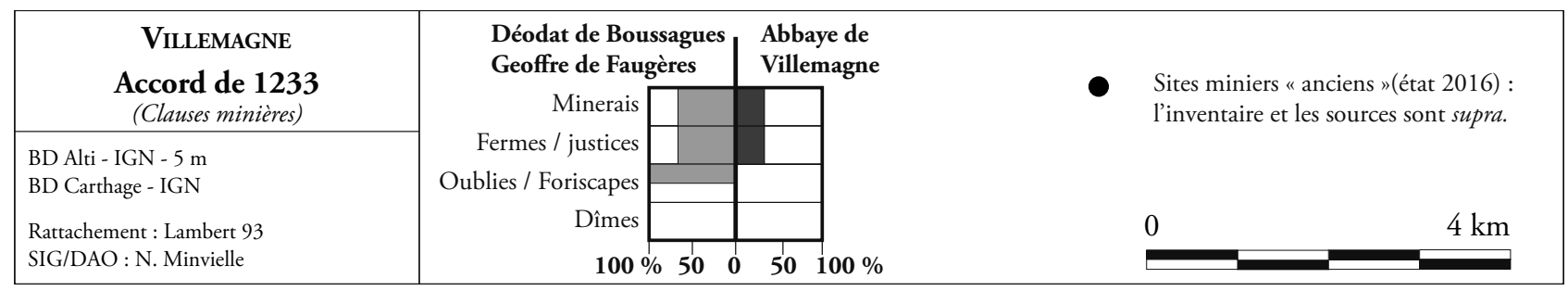

Fig. 23 : Répartition des droits miniers issus de l'accord de 1233.

avoir fixé et fait perdurer l'activité pendant plusieurs dizaines d'années. Donc, avec ce partage, chacun des coseigneurs était servi : Déodat et Geoffre se partageaient le Pradal, de loin le réseau le plus vaste ; alors que l'abbaye était majoritaire à Taussac et exclusive à Capmal, tout en réussissant même à percevoir la dîme du Pradal. La répartition des revenus provenant des autres manses ménage également les parties, puisque chacun des trois coseigneurs en recevait le tiers. Sur ces derniers, les enjeux étaient de toute façon plus réduits, car les gisements polymétalliques, bien que nombreux, étaient dispersés et individuellement peu importants. Les activités s'étaient manifestement polarisées autour des trois exploitations du Pradal, Taussac, Capmal avec leurs ateliers de traitement, tandis qu'en parallèle d'autres travaux étaient plus ou moins suivis sur le moindre affleurement minéralisé environnant.

\section{CONCLUSION}

À la lumière de ses textes et de ses vestiges, un espace minier dynamique et attractif s'est dessiné autour de Villemagne. Active dès avant la seconde moitié du $\mathrm{XII}^{\mathrm{e}}$ siècle pour s'achever au début du $\mathrm{XIV}^{\mathrm{e}}$ siècle, sa production polymétallique était fondée sur des gisements argentifères aux tailles et aux formes variées. Mais ils semblent avoir tous été prospectés et exploités avec la même intensité. Ce systématisme se remarque autant dans le nombre de gisements abattus, même les plus petits ont été pris en compte, que dans la qualité des travaux, eu égard aux très rares lentilles minéralisées restantes. Bien que la phase médiévale de l'exploitation ne soit peut-être pas seule responsable de cette observation, il n'en reste pas moins que ses mineurs avaient une excellente connaissance du potentiel argentifère de leur espace. La confrontation du territoire minier construit en 


\begin{tabular}{|c|c|c|c|c|c|c|c|c|c|c|c|c|}
\hline & \multicolumn{3}{|c|}{ TAUSSAC } & \multicolumn{3}{|c|}{ LA BLAQUIÈRE } & \multicolumn{3}{|c|}{ ROIRE } & \multicolumn{3}{|c|}{ LES BOURDELLES } \\
\hline & Minerais & $\begin{array}{l}\text { Justice et } \\
\text { fermes }\end{array}$ & $\begin{array}{l}\text { Oublies et } \\
\text { foriscapes }\end{array}$ & Minerais & $\begin{array}{l}\text { Justice et } \\
\text { fermes }\end{array}$ & $\begin{array}{l}\text { Oublies et } \\
\text { foriscapes }\end{array}$ & Minerais & $\begin{array}{l}\text { Justice et } \\
\text { fermes }\end{array}$ & $\begin{array}{l}\text { Oublies et } \\
\text { foriscapes }\end{array}$ & Minerais & $\begin{array}{l}\text { Justice et } \\
\text { fermes }\end{array}$ & $\begin{array}{l}\text { Oublies et } \\
\text { foriscapes }\end{array}$ \\
\hline $\begin{array}{l}\text { Abbaye de } \\
\text { Villemagne }\end{array}$ & $3 / 4$ & $2 / 3$ & $1 / 1$ & $1 / 3$ & $1 / 3$ & $0 / 1$ & $1 / 3$ & $1 / 3$ & $0 / 1$ & $1 / 3$ & $1 / 3$ & $0 / 1$ \\
\hline $\begin{array}{l}\text { Déodat de } \\
\text { Boussagues }\end{array}$ & \multirow{2}{*}{$1 / 4$} & \multirow{2}{*}{$1 / 3$} & \multirow{2}{*}{$0 / 1$} & \multirow[b]{2}{*}{$2 / 3$} & \multirow{2}{*}{$2 / 3$} & $1 / 1$ & \multirow{2}{*}{$2 / 3$} & \multirow[b]{2}{*}{$2 / 3$} & $1 / 1$ & \multirow{2}{*}{$2 / 3$} & \multirow[b]{2}{*}{$2 / 3$} & $1 / 1$ \\
\hline $\begin{array}{l}\text { Geoffroy de } \\
\text { Faugères }\end{array}$ & & & & & & $?$ & & & $?$ & & & $?$ \\
\hline
\end{tabular}

\begin{tabular}{|c|c|c|c|c|c|c|c|c|c|}
\hline & \multicolumn{3}{|c|}{ LA ROQUE } & \multicolumn{3}{c|}{ LE PRADAL } & CAPMAL & \multicolumn{2}{c|}{ CLAIRAC } \\
\hline & Minerais & $\begin{array}{c}\text { Justice et } \\
\text { fermes }\end{array}$ & $\begin{array}{c}\text { Oublies et } \\
\text { foriscapes }\end{array}$ & Minerais & Dîme & $\begin{array}{c}\text { Justice et } \\
\text { fermes }\end{array}$ & Ensemble & Minerais & $\begin{array}{c}\text { Justice et } \\
\text { fermes }\end{array}$ \\
\hline \hline $\begin{array}{c}\text { Abbaye de } \\
\text { Villemagne }\end{array}$ & $1 / 3$ & $1 / 3$ & $0 / 1$ & $0 / 1$ & $1 / 1$ & $0 / 1$ & $1 / 1$ & $1 / 3$ & $1 / 3$ \\
\hline \hline $\begin{array}{c}\text { Déodat de } \\
\text { Boussagues }\end{array}$ & $2 / 3$ & $2 / 3$ & $1 / 1$ & $1 / 1$ & $0 / 1$ & $1 / 1$ & $0 / 1$ & $2 / 3$ & $2 / 3$ \\
\cline { 1 - 11 } $\begin{array}{c}\text { Geoffroy de } \\
\text { Faugères }\end{array}$ & & $?$ & $1 / 1$ & & & \\
\hline
\end{tabular}

Fig. 24 : Redevances minières contenues dans l'accord de 1233

1164 avec les ressources polymétalliques et les divers travaux anciens répertoriés est à cet égard significative. C'est d'ailleurs là que réside l'un des principaux intérêts de cet espace minier. Il offre la possibilité de croiser les sources et ainsi de nourrir des commentaires interdisciplinaires, à même d'éclairer certains enjeux de pouvoirs ou d'expliquer certaines organisations sociales et rapports qu'entretenaient les acteurs de la production.

Ainsi, et au-delà des premières hypothèses proposées, la synthèse formalisée à l'occasion de la prospection de 2016 rend possible et appelle un programme d'étude plus ambitieux. Cet état de l'art ne pourra en effet être dépassé sans qu'une chronologie archéologique de la production soit construite, nécessitant de multiplier les sondages sur les travaux mineurs, et de comprendre les dynamiques d'exploitation des travaux majeurs. À partir de corpus périodisés, il sera alors envisageable d'engager des études techniques poussées, et de réfléchir sur l'organisation sociale de la production. Enfin, l'espace minier de Villemagne était l'une des sources de métaux polymétalliques, diffusés et utilisés, a minima, dans le Languedoc médiéval. Les circuits de l'argent, mais aussi du plomb et du cuivre devront être reconstruits à partir de méthodes géochimiques, en lien avec les ateliers monétaires proches de même qu'avec les divers ateliers, objets et matériaux métalliques.

\section{Remerciements}

Cette étude a été collective et soutenue par des institutions et collègues que nous tenons à remercier chaleureusement : le Service Régional de l'Archéologie Occitanie pour son soutien scientifique et financier, et en particulier Henri Marchesi, Philippe Galant, Hélène Breichner; le Conseil Départemental de l'Hérault pour son soutien financier, et en particulier Patricia
Beaudoin ; le Groupe d'Étude des Mines Anciennes pour l'efficace réalisation de cette opération, dont Flavien Perazza son président et les participants à la prospection, Clément Denizeau, François Gaspard, Sarah Laurent, Léa Métivier, Louis Renouard, Rémi Saou, Élise Seron ; enfin Michel Berbigé et Michel Salvaire pour leur accueil et leur aide amicale.

\section{BIBLIOGRAPHIE}

Amado 1977 : AMADO (C.), La seigneurie des mines en pays de Béziers et en Razès. Analyse de trois documents de la seconde moitié du XII ${ }^{e}$ siècle, in : Mines et mineurs en Languedoc-Roussillon et régions voisines: de l'Antiquité à nos jours, Montpellier, Fédération historique du Languedoc méditerranéen et du Roussillon, 1977, p. 125-144.

Amado 2001 : AMADO (C.), Genèse des lignages méridionaux. Tome I, L'aristocratie languedocienne $d u X^{e}$ au XII siècle, Toulouse, CNRS-Université de Toulouse-Le Mirail, coll. " Méridiennes », 2001, $534 \mathrm{p}$.

Amado 2007 : AMADO (C.), Genèse des lignages méridionaux. Tome 2, Portraits de familles, Toulouse, CNRS-Université de Toulouse-Le Mirail, coll. « Méridiennes », 2007, 456 p.

Ambert et al. 1996 : AMBERT (P.), CAROZZA (L.), LÉCHELON (B.), HOULES (N.), De la mine au métal au sud du Massif Central au Chalcolithique (Données nouvelles: régions de Cabrières, Fayet, Villefranche de Rouergue), in : AMBERT (P.), éd., Cabrières - Hérault et le contexte régional du développement de la première métallurgie du cuivre en France (III millénaire av. J.-C.), Archéologie en Languedoc, 20, 1996, p. 35-42. 
Béchiri 1999 : BÉCHIRI (B.), Prospections minières sur les Hauts-Cantons de l'Hérault. Histoire des techniques de la protohistoire au XVIII siècle et archéologie industrielle, Montpellier, Service Régional de l'Archéologie Languedoc-Roussillon, 1999, 42 p.

Béchiri 2001 : BÉCHIRI (B.), Prospections minières sur les Hauts-Cantons de l'Hérault. Programme 25 : histoire des techniques de la protohistoire au XVIII siècle et archéologie industrielle, Montpellier : Service Régional de l'Archéologie LanguedocRoussillon, 2001, 44 p.

Bellan, Christol 1986 : BELLAN (G.), CHRISTOL (M.), Une inscription romaine à Villemagne l'Argentière : le site de Saint-Martin-le-Vieux, Bulletin de la Société Archéologique et Historique des Hauts Cantons de l'Hérault, 9, 1986, p. 33-44.

Blaquière 1998 : BLAQUIÈRE (H.), Les archives de la maison de Thézan, Société Archéologique Scientifique et Littéraire de Béziers, III, 1998.

Bonsangue 2011 : BONSANGUE (M.-L.), Administrer et exploiter les mines en Gaule Méridionale : le rôle de Narbonne ( $\mathrm{I}^{\mathrm{er}}$ siècle av. J.-C.- $\mathrm{II}^{\mathrm{e}}$ siècle ap. J.-C., in : BENOIST (S.), DAGUET-GAGEY (A.), HOËTVAN CAUWENBERGHE (C.), éd., Figures d'empire, fragments de mémoire: pouvoirs et identités dans le monde romain impérial (II $s . a v . n$. è. - VI $s$. de n. è.), Villeneuve d'Ascq, Presses universitaires du Septentrion, 2011, p. 361-384

Boussard, Monicat 1946 : BOUSSARD (J.), MONICAT (J.), éd., Recueil des actes de Philippe Auguste, roi de France, 3, Paris : Impr. nationale, coll. " Chartes et diplômes relatifs à l'histoire de France », 1946, 555 p.

Cambon et al. 1986 : CAMBON (C.), FILIPPO (R.) de, GRACIA (Y.), PEIXOTO (X.), SAUVAGE (C.), Un exemple d'inventaire de mines antiques : l'est de la Montagne Noire, in : DEICHA (G.), BRAEMER (F.), éd., Les ressources minérales et l'histoire de leur exploitation, Paris, Comité des travaux historiques et scientifiques, 1986, p. 77-89.

Chaillou, Thomas 2007 : CHAILLOU (A.), THOMAS (J.), L'application Patriarche, Les nouvelles de l'archéologie, 107, 2007, p. 52-57.

Charles et al. 2009 : CHARLES (N.), FAURE (M.), CHEN (Y.), The Montagne Noire migmatitic dome emplacement (French Massif Central): new insights from petrofabric and AMS studies, Journal of Structural Geology, 31, 11, 2009, p. 1423-1440.

Clavel-Lévêque 1970 : CLAVEL-LÉVÊQUE (M.), Béziers et son territoire dans l'Antiquité, Paris, Les Belles Lettres, 1970, 664 p.

Daubrée 1868 : DAUBRÉE (A.), Aperçu historique sur l'exploitation des métaux dans la Gaule, Revue Archéologique, 1868, p. 1-16.

Débax 2008 : DÉBAX (H.), Pairs, pariers, paratge: coseigneurs et seigneurie collective $X I^{e}-X I I I^{e}$ siècle, Thèse d'HDR, Université Toulouse-Le-Mirail, 2008.
Débax 2012 : DÉBAX (H.), La Seigneurie collective: pairs, pariers, paratge les coseigneurs $d u X I^{e}$ au $X I I I^{e}$ siècle, Rennes, Presses Universitaires de Rennes, coll. « Histoire », 2012, 463 p.

Filippo et al. 1982 : FILIPPO (R.) de, GRACIA (Y.), PEIXOTO (X.), SAUVAGE (C.), Inventaire et étude des mines antiques des Pyrénées, Cévennes et Limousin: Tranche 1, Est de la montagne noire, Toulouse, 1982.

Gensanne 1779 : GENSANNE (A.) de, Histoire naturelle de la province de Languedoc, Montpellier, Chez Rigaud, Pons \& compagnie, 1779.

Gèze 1995 : GÈZE (B.), Languedoc méditerranéen, Montagne noire, Paris, 1995, $191 \mathrm{p}$.

Gonord 1966 : GONORD (H.), Contribution à l'étude des gîtes minéraux de la terminaison Est de la Montagne Noire, Thèse, Université de Montpellier, Faculté des sciences, 1966, 131 p.

Gourdiole 1980 : GOURDIOLE (R.), Mont-Coudour. Mine et halde historique, Montpellier, Service Régional de l'Archéologie Languedoc-Roussillon, 1980, 5 p.

Gourdiole, Guiraud 1992 : GOURDIOLE (R.), GUIRAUD (R.), Révision de la carte archéologique. Canton de Lunas, canton d'Olargues, Montpellier, SRA Languedoc-Roussillon, 1992, 186 p.

Guiraud, Gourdiole 1978 : GUIRAUD (R.), GOURDIOLE (R.), Fouille de l'entrée de la galerie mine de Clairac. Commune de La Tour-sur-Orb (Hérault), Montpellier, Service Régional de l'Archéologie Languedoc-Roussillon, 1978, 6 p.

Hesse 1968 : HESSE (P.-J.), La mine et les mineurs en France de 1300 à 1550, Thèse de doctorat d'État en droit, Paris, Université de Paris, 1968, 804 p.

Journot 1990 : JOURNOT (F.), Archéologie des châteaux médiévaux de la montagne héraultaise: haut bassin de l'Orb et bassin de la Lergue, Thèse de doctorat, Université de Haute-Bretagne, Rennes 2, 1990, $313 \mathrm{p}$.

Journot 1992 : JOURNOT (F.), Notes sur l'exploitation des ressources minières en montagne héraultaise au Moyen Âge, Bulletin de la Société archéologique des hauts cantons de l'Hérault, 15, 1992, p. 43-52.

Journot 2013 : JOURNOT (F.), Le bourg abbatial de Villemagne-l'Argentière (Hérault): dynamique économique et commande monumentale $X I^{e}$ $X I V^{e}$ siècles, s.1., BAR International Series 2561, 2013, $253 \mathrm{p}$

Kammenthaler $\boldsymbol{e t}$ al. 2016 : KAMMENTHALER (E.), MINVIELLE LAROUSSE (N.), PIERRE (F.), Villefort 1640 : l'introduction de la poudre dans les mines languedociennes, Archéologie Médiévale, 46, 2016, p. $135-156$

Lamotte et al. 2011 : LAMOTTE (C.), GIRONDE C.), LADOUCHE (B.), Ressource en eau thermale de la station de Lamalou-Les-Bains - Etat des lieux. Rapport final, BRGM/RP - 59921 - FR, 2011, 106 p. 
Léchelon 2011 : LÉCHELON (B.), Argent rutène et entrepreneurs romains aux confins de la Transalpine, in : GRUAT (P.), PAILLER (J.-M.), SCHAAD (D.), éd., Les Rutènes: du peuple à la cité, de l'indépendance à l'installation dans le cadre romain 150 a.C. - 100 p.C.), Bordeaux, Aquitania, 2011, p. 245-279.

Mahul 1857 : MAHUL (A.), Cartulaire et archives des communes de l'ancien diocèse et de l'arrondissement administratif de Carcassonne, Paris, V. Didron, 1857.

Mantenant 2014 : MANTENANT (J.), Montagnes métallifères de Gaule méditerranéenne. Approche archéologique et historique de la production des métaux en Languedoc occidental du début du second âge du Fer à la fin de la période romaine (IVe s. av. $n$. è. $-V^{e} s$. de n. è.), Thèse de doctorat, Université de Toulouse-Le Mirail, 2014, 481, 203 et 144 p.

Minvielle Larousse 2016 : MINVIELLE LAROUSSE (N.), Villemagne l'Argentière. Rapport de prospections thématiques, Montpellier, Service Régional de l'Archéologie Languedoc-Roussillon, 2016, 267 p.

Minvielle Larousse 2017 : MINVIELLE LAROUSSE (N.), L'âge de l'argent. Mines, société et pouvoirs en Languedoc médiéval, Thèse de doctorat d'archéologie médiévale, Aix-Marseille Université, 2017, $1365 \mathrm{p}$.

Munteanu et al. 2017 : MUNTEANU (G.), KAMMENTHALER (E.), MANTENANT (J.), RICO (C.), FABRE (J.-M.), BEYRIE (A.), Le complexe minier gaulois des Barrencs (Aude, France) dans son contexte géologique et minéralogique, ArchéoSciences, 40, 2017, p. 163-180.

Pasquier 1900 : PASQUIER (F.), Recueil des chartes de Boussagues, Bulletin de la Société archéologique, scientifique et littéraire de Béziers, 3, 1900, p. 243-412.

Pasquier 1901 : PASQUIER (F.), Documents relatifs à la seigneurie de Boussagues, Hérault, de la fin du $X I I^{e}$ au milieu du XIV siècle, Béziers, J. Sapte, 1901, $164 \mathrm{p}$.

Pasquier, Olive 1913 : PASQUIER (F.), OLIVE (S.), Le fonds Thézan aux archives du château de Léran, Ariège: documents concernant diverses localités du département de l'Hérault, Montpellier, Lauriol, $1913,559 \mathrm{p}$.

Pierre 1992 : PIERRE (F.), Datation des travaux miniers à la poudre. Essais de typologie, in : Les techniques minières de l'Antiquité au XVIII ${ }^{e}$ siècle: actes du colloque international sur les ressources minières et l'histoire de leur exploitation de l'Antiquité à la fin du XVIII siècle réuni dans le cadre du $113^{e}$ Congrès national des sociétés savantes (Strasbourg, 5-9 avril 1988), Paris, éd. du CTHS, coll. « Actes du Congrès national des sociétés savantes. Section d'histoire des sciences et des techniques », 1992, 113, p. 519-527.
Pierre 2015 : PIERRE (F.), La poudre noire : de l'engin pyrotechnique incendiaire au tir de mine, in : JALABERT (L.), MULLER V., éd., Conflits et progrès scientifiques et techniques en Lorraine à travers les siècles : actes du colloque, 17 et 18 octobre 2014, Metz, Moyenmoutier, Edhisto, 2015, p. 141-159.

Poux 1899 : POUX (J.), Notes et documents sur les mines de charbon de Boussagues en Bas-Languedoc, aux XIII ${ }^{\mathrm{e}}$ et $\mathrm{XIV}^{\mathrm{e}}$ siècles, Bulletin historique et philologique du comité des travaux historiques et scientifiques, 1899, p. 326-353.

Py 2017 : PY (M.), Syslat-Terminal 5.0. Manuel d'utilisation, Lattes, CNRS, 2017.

Rouquette 1918 : ROUQUETTE (J.), éd., Cartulaire de Béziers (livre noir), Paris, Picard, 1918, 570 p.

Sainte-Marthe 1739 : SAINTE-MARTHE (D.) de, Provincia Narbonensi, Paris, J. B. Coignard, coll. « Gallia Christiana », 6, 1739, 895 p.

Vergani 1979 : VERGANI (R.), Gli inizi dell'uso della polvere da sparo nell'attività mineraria : il caso veneziano, Studi Veneziani, III, 1979, p. 97-140.

Vergani 2003 : VERGANI (R.), Gli usi civili della polvere da sparo (secoli XV-XVIII), in : CAVACIOCCHI (S.), éd., Economia e energia, secc. XIIIXVIII, Firenze, Le Monnier, coll. « Istituto internazionale di storia economica F. Datini, Prato. Serie 2., Atti delle Settimane di studi e altri convegni », 34, 2003, p. 865-878.

Verna 1999 : VERNA (C.), Medieval coalmining in the seigneury of Boussagues (Hérault-France), in : BENOIT (P.), VERNA (C.), éd., Le charbon de terre en Europe occidentale avant l'usage industriel du coke, Proceedings of the XXth International Congress of History of Science, Turnhout, Brepols, 1999, p. 31-39.

Vic, Vaissète 1874 : VIC (C.) de, VAISSÈTE (J.), Histoire générale de Languedoc: avec des notes et des pièces justificatives, Toulouse, Privat, 1874. 
